\title{
Guidelines
}

\section{e Comprehensive Consensus Based Guidelines on Intrathecal Drug Delivery Systems in the Treatment of Pain Caused by Cancer Pain}

Timothy R. Deer, MD'; Howard S. Smith, MD²; Allen W. Burton, MD; Jason E. Pope, MD'; Daniel M. Doleys, $\mathrm{PhD}^{4}$; Robert M. Levy, MD, PhD ${ }^{5}$; Peter S. Staats, $\mathrm{MD}^{6}$; Mark Wallace, $\mathrm{MD}^{7}$; Lynn R. Webster, MD; Richard Rauck, MD'; and Michael Cousins, MD ${ }^{10}$

From: ${ }^{1}$ The Center for Pain Relief, Inc., Charleston, WV; ${ }^{2}$ Albany Medical College, Albany, NY; ${ }^{3}$ University of Texas Anderson Cancer Center, Houston, TX; ${ }^{4}$ Royal North Shore Hospital, St. Leonards, Sydney, Australia; 5Pain and Rehabilitation Institute, Birmingham, AL ${ }^{6}$ Northwestern University Feinberg School of Medicine, Chicago, IL; 'Johns Hopkins University, Baltimore, MD; ${ }^{8}$ University of California, San Diego, CA; Lifetree Clinical Research and Pain Clinic, Salt Lake City, Utah; ${ }^{10}$ Wake Forest University Health Sciences, Winston-Salem, NC

Address correspondence: Timothy R Deer, MD The Center for Pain Relief, 400 Court Street, Suite 304 Charleston, WV

E-mail: Doctdeer@aol.com

Full disclosures on page $E_{305}$.

Manuscript received: ol/05/2011

Revised manuscript received: 03/01/2011

Accepted for publication: 04/07/2011

Free full manuscript: www.painphysicianjournal. com
Background: Chronic persistent pain as a result of terminal illness, either as a consequence of the disease or the necessary treatment, is common in patients with cancer. For these patients with moderate-to-severe intractable pain, intrathecal (IT) drug delivery systems may represent an effective option for pain management. Thus, IT drug delivery is a viable treatment strategy for both neuropathy and nociceptive pain in the cancer population. However, there is a scarcity of comprehensive guidelines in implanting IT drug delivery systems in the treatment of pain caused by cancer.

Objective: This article outlines consensus guidelines for the implementation of intrathecal therapy in patients with cancer-related pain and other end of life states causing pain. We highlight the multidisciplinary criteria that warrant careful consideration to ensure meaningful analgesia.

Methods: Evidence was compiled, ranked, and strength considered by an invited panel of wellpublished and innovative clinician research leaders in pain medicine. Based on that analysis, an accumulation of evidence from observational and randomized prospective trials supports the use of intrathecal (IT) drug delivery to provide effective analgesia for patients with cancer-related pain, including individuals at the end of life. Although not all patients are candidates for this invasive treatment modality, clinicians can determine the appropriateness of proceeding with device implantation by carefully evaluating the individual's overall medical status, psychological stability, social support system, and prognosis of disease. Further, consumption of health care resources and cost-effective treatment is becoming more of a priority; not only is this therapy appropriate medically, but also economically. This multifaceted approach to patient selection assists in maximizing treatment effect and avoiding unintended consequences of therapy.

Limitations: The limitations of these guidelines include that these are of expert panel guidelines. The literature describes appropriate preparation of guidelines based on evidence derived from randomized trials and systematic reviews. However, there is also value for consensus-based guidelines due to non-availability of evidence from either systematic reviews of randomized trials or randomized trials alone. In addition, the evidence is not available on many aspects of intrathecal infusion systems even with observational studies and case reports. Thus, the present approach with expert consensus guidelines is acceptable.

Conclusions: These consensus guidelines are intended to assist clinicians in identifying the candidacy of patients with cancer-related pain and end of life diseases causing pain that may benefit from intrathecal drug delivery. With careful consideration of the patient's medical comorbidities and prior therapies, communication with the oncologist, proper psychological evaluation, and appropriate trialing technique, clinicians can effectively optimize the use of IT therapy for cancer pain. The panel advocates for a much wider application of IT therapy to provide meaningful analgesia for patients with cancer pain, including those at the end of life from a variety of causes.

Key words: Intrathecal, cancer, palliative, pain, guidelines, opioids, consensus, selection, evidence

Pain Physician 2011; 14: E283-E312 
Many patients suffer from moderate to severe pain as a result of terminal illness, either as a consequence of the disease or the necessary treatment $(1,2)$. For these patients with moderate-to-severe intractable pain, intrathecal (IT) drug delivery systems may represent an effective option for pain management (3-9). By positioning a catheter in the cerebral spinal fluid, IT therapy allows drugs to be applied directly to the receptors of the central nervous system (CNS), reducing enteral side-effects, and greatly reducing systemic dose. Long term IT therapy therefore necessitates that a pump be surgically placed in the subcutaneous tissue such that it acts as a drug reservoir and delivery mechanism, thus allowing for the administration of a variety of opioid and nonopioid agents (6-10).

Intrathecal drug delivery is a viable treatment strategy for both neuropthic and nociceptive pain in the cancer population, as highlighted by the available randomized trials and observational studies (6-9,11-33). Prospective randomized studies have shown improved pain relief and decreased adverse effects in these patient populations, compared with conventional medical management alone (1,3-9,11-33). Further IT drug infusion systems have been used to treat end-of-life pain associated with various disease states, including pain related to cancer and acquired immunodeficiency syndrome (AIDS) (3). The mechanisms of various drugs have been well-studied (34-53) However, this therapy is not without consequence or controversy (6).

Importantly, not all patients at end of life are appropriate candidates for IT therapy; the decision to proceed with device implantation is complicated and requires careful evaluation of multifaceted therapeutic

Table 1. Classifications of breakthrough pain

- Spontaneous pain (also known as idiopathic pain): pain that occurs unexpectedly

- Incident pain (also known as precipitated pain or, when appropriate, movement-related pain): pain that is related to specific events and can be subclassified into 3 categories

- Volitional-pain that is precipitated by a voluntary act (e.g., walking).

- Nonvolitional-pain that is precipitated by an uninvoluntary act (e.g., coughing).

- Procedural-pain that is related to a therapeutic intervention (e.g., wound dressing).

- End-of-dose failure: this type of pain is related to analgesic dosing (i.e., declining analgesic levels). measures to ensure optimal treatment outcomes $(7,8)$. When considering a pump, clinicians must consider comorbidities related to disease and psychosocial factors such as death and dying issues, and life expectancy.

Proper patient selection, implantation technique, maintenance, and continued vigilance are paramount to reduce predictable iatrogenic complications and ensure success (54). To that end, the expert panel was formed to assimilate the available evidence into guidelines and provide strength scores to their recommendations for clinically relevant management decisions.

\subsection{Differentiating Cancer-elated Pain versus Pain from Other Etiologies}

Pain affects a staggering number of individuals and is particularly common among patients with cancer. Indeed, the prevalence of pain has been reported to be $30 \%$ to $40 \%$ for patients with early disease, with estimates as high as $70 \%$ to $90 \%$ for patients with advanced disease (9). A recent meta-analysis by van den Beuken-van Everdingen et al (1) reviewed 52 studies and found a prevalence of pain in advanced, incurable cases to be approximately $64 \%$, with an incidence of chronic pain after cure of 33\%. Furthermore, these authors found that $33 \%$ of that reported pain was in the moderate-to-severe range.

In addition, patients with cancer pain also may suffer with pain of non-cancer origin, which is highly prevalent and increasing (2). Further, while it is difficult to diagnose chronic pain in general, utilizing multiple interventional techniques, chronic pain may be successfully diagnosed and also treated with various modalities of treatments (55-93).

Cancer pain and its treatment tends to differ from noncancer pain in a multitude of ways, including a significantly poorer prognosis often with shortened life spans, reduced need for complete restoration of function, multiple sites and/or types of cancer pain, patient perception or interpretation of the meaning of pain, as well as disparities related to therapeutic approaches (e.g., radiopharmaceuticals for painful osseous metastases) (94).

Patients with cancer-related pain are often subject to episodes of breakthrough pain, defined by Portenoy et al (95) as "a transitory exacerbation of pain experienced by the patient who has relatively stable and adequately controlled baseline pain." Breakthrough pain can be classified according to its relationship to specific events or to analgesic dosing (Table 1) (96). Although 
there exists large variability regarding the prevalence of breakthrough pain (97-107), it seems reasonable to estimate that roughly two-thirds of patients experience this symptom (105-109).

Empirical evidence suggests that cancer of the bone is the most painful site. Patients typically report pain and/or tenderness immediately over the site of the osseous metastasis; however, multiple pain syndromes have been characterized by various pain referral patterns. A working appreciation of these and other referral patterns will help clinicians ensure that diagnostic imaging is directed to the appropriate location (107).

\subsection{Current Evidence for IT Therapy}

Over the past 2 decades, IT therapy has increasingly become an accepted alternative to standard medical management for cancer patients with moderate-to-severe intractable pain $(86,87)$. Utilizing the wide variety of available agents, IT drug delivery devices enable clinicians to formulate individualized treatment regimens that can provide effective analgesia with potentially fewer adverse effects than traditional opioid-based therapies (Fig. 1) (6).

Numerous prospective and/or randomized controlled trials have evaluated the use of implantable drug delivery systems in patients at the end of life, whether due to cancer or other terminal illness (Table 2) $(3,4,6$ 9,11-20). Results from these trials have demonstrated that IT therapy can effectively reduce neuropathic and

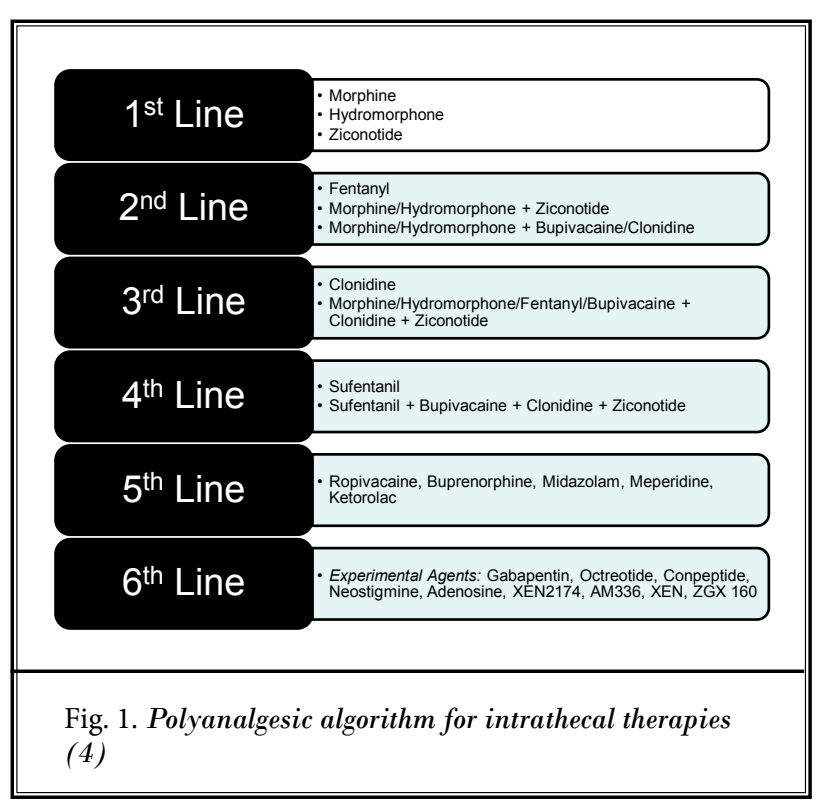

www.painphysicianjournal.com mixed neuropathic-nociceptive pain in cancer patients, while relieving drug-related toxicities $(4,11)$ and minimizing the need for supplementary systemic opioids (11). Similarly, a prospective randomized study by Staats et al (3) found that patients with pain attributed to AIDS experienced clinically and statistically significant analgesia when treated via an implantable device, emphasizing the range of disease states in which IT therapy is effective.

Recent data exemplifying the benefits of IT drug delivery on improvements in physical and mental functioning are less robust than the evidence supporting its use for pain management (110-112). A prospective study by Thimineur et al (113) reported improvements in pain, mood, and function from baseline to 36 months in participants implanted with a drug delivery system, whereas participants who were not treated via an IT device showed a considerable decline in physical function, depression, and anxiety scores.

\subsection{Clinical Implications of IT Drug Delivery}

Although the potential therapeutic benefit of IT therapy has been well documented in the literature, researchers have identified several adverse effects and complications associated with this invasive treatment $(6,11,13,108,109,113-116)$.

The 2007 Interdisciplinary Polyanalgesic Conference recommendations outline the potential clinical consequences-including opioid-induced hyperalgesia, hypotension, sedation, respiratory depression, inflammatory mass, hypogonadotropic hypogonadism, and immunologic compromise-that can result from IT therapy $(6,117,118)$. Although the potential for these consequences can be diminished with careful dosing and titration, they are not completely precluded. Excess mortality can also result from dose escalation that occurs too quickly and in the absence of proper monitoring, particularly in the 24 hours immediately following drug initiation $(14,115)$. Although Coffey et al (115) reported that intrathecal therapy may increase morbidity and mortality in treating noncancer pain as a reflection of inappropriate dosing and respiratory compromise, these concerns can be translated to the cancer population. To limit the potential for adverse effects, the panel recommended that therapy be initiated at low doses, with slow titration upward, as necessary, based on patient response (6). In end-of-life care, however, titration of supportive care medications, including IT agents, should be done expediently, acknowledging 
Table 2. Prospective and randomized controlled studies of IT therapy

\begin{tabular}{|c|c|c|c|c|c|}
\hline Study & Participants & Follow-up & Intervention & Results & Conclusion \\
\hline $\begin{array}{l}\text { Smith et al (4) } \\
\text { 2002; double-blind, } \\
\text { placebo-controlled } \\
\text { randomized trial; } \\
\text { follow-up trial pub- } \\
\text { lished by Smith et al } \\
\text { (5) in } 2005\end{array}$ & $\begin{array}{l}\text { Patients with intrac- } \\
\text { table cancer pain were } \\
\text { randomized to receive } \\
\text { either CMM or an im- } \\
\text { plantable drug delivery } \\
\text { system in combination } \\
\text { with CMM ( } \mathrm{n}=202) \text {; } \\
\text { primary end point was } \\
\text { control (VAS measure) } \\
\text { and change in toxicity }\end{array}$ & 4 weeks & $\begin{array}{l}\text { Patients with an im- } \\
\text { plantable device received } \\
\text { IT morphine; other IT } \\
\text { agents were used if mor- } \\
\text { phine failed to produce } \\
\text { appropriate results }\end{array}$ & $\begin{array}{l}84.5 \% \text { of patients } \\
\text { in the IT therapy } \\
\text { cohort achieved } \\
\text { clinical success } \\
\text { compared with } \\
70.8 \% \text { in the } \\
\text { CMM group ( } P \\
=.05)\end{array}$ & $\begin{array}{l}\text { Significant reductions } \\
\text { in fatigue and depressed } \\
\text { level of consciousness } \\
\text { were reported in the IT } \\
\text { therapy cohort }(P<.05) \text {; } \\
\text { patients implanted with a } \\
\text { drug delivery device had } \\
\text { better survival rates at } 6 \\
\text { months compared with } \\
\text { the CMM cohort (53.9\% } \\
\text { vs } 37.2 \% \text {, respectively; } \\
P=.06 \text { ); IT therapy also } \\
\text { improved pain manage- } \\
\text { ment and alleviated com- } \\
\text { mon drug toxicities }\end{array}$ \\
\hline $\begin{array}{l}\text { Rauck et al (11) } \\
\text { 2003; prospective } \\
\text { open-label study }\end{array}$ & $\begin{array}{l}119 \text { patients with refrac- } \\
\text { tory cancer pain and/ } \\
\text { or intolerable adverse } \\
\text { effects were enrolled at } \\
17 \text { US and international } \\
\text { sites to receive an im- } \\
\text { plantable drug delivery } \\
\text { system; reduction in } \\
\text { pain, systemic opioid } \\
\text { use, and opioid-related } \\
\text { adverse effects were } \\
\text { analyzed }\end{array}$ & $\begin{array}{l}\text { Up to } 4.7 \text { years } \\
\text { (data presented } \\
\text { over } 16 \text { months } \\
\text { post-implanta- } \\
\text { tions) }\end{array}$ & $\begin{array}{l}\text { Patients received a } \\
\text { patient-activated drug } \\
\text { delivery system with } \\
\text { morphine sulfate }\end{array}$ & $\begin{array}{l}\text { Overall success ( } \geq \\
50 \% \text { reduction in } \\
\text { numeric analog } \\
\text { scale score, use of } \\
\text { systemic opioids, } \\
\text { or opioid com- } \\
\text { plication severity } \\
\text { index) was re- } \\
\text { ported in } 83 \% \text { at } \\
\text { month one, } 90 \% \\
\text { at month } 2,85 \% \\
\text { at month } 3 \text {, and } \\
91 \% \text { at month } 4\end{array}$ & $\begin{array}{l}\text { Use of patient-activated } \\
\text { drug delivery system } \\
\text { resulted in effective anal- } \\
\text { gesia and fewer adverse } \\
\text { effects }\end{array}$ \\
\hline $\begin{array}{l}\text { Staats et al (3) } \\
\text { 2004; prospective } \\
\text { randomized trial }\end{array}$ & $\begin{array}{l}\text { Patients with cancer or } \\
\text { AIDS were randomized } \\
\text { to receive ziconotide } \\
\text { or placebo }(\mathrm{n}=111) \text {; } \\
\text { all participants had a } \\
\text { mean VASPI score of } \geq \\
50 \mathrm{~mm}\end{array}$ & 11 days & $\begin{array}{l}\text { IT ziconotide was } \\
\text { titrated over } 5 \text { to } 6 \text { days, } \\
\text { followed by a } 5 \text {-day } \\
\text { maintenance phase for } \\
\text { responders and cross- } \\
\text { over of nonresponders } \\
\text { to the opposite cohort }\end{array}$ & $\begin{array}{l}\text { Mean VASPI } \\
\text { scores improved } \\
53.1 \% \text { in the } \\
\text { ziconotide cohort } \\
\text { compared with } \\
18.1 \% \text { in the } \\
\text { placebo group ( } P \\
<.001) ; 52.9 \% \text { of } \\
\text { patients in the } \\
\text { active treatment } \\
\text { group reported } \\
\text { moderate-to- } \\
\text { complete pain } \\
\text { relief compared } \\
\text { with } 17.5 \% \text { in the } \\
\text { placebo cohort }(P \\
<.001)\end{array}$ & $\begin{array}{l}\text { IT ziconotide dem- } \\
\text { onstrated significant } \\
\text { improvements in pain in } \\
\text { patients with cancer- or } \\
\text { AIDS-related pain }\end{array}$ \\
\hline
\end{tabular}

IT = intrathecal; CMM = comprehensive medical management; VASPI = Visual Analog Scale of Pain Intensity; AIDS = acquired immune deficiency syndrome.

that the regard for upper limits on doses and concentrations should be flexible according to patient need.

When dose escalation is no longer deemed safe with monotherapy, clinicians may prescribe combination therapy to maintain effective analgesia. Many of these algorithms are not labeled for use by the FDA in the United States, but are acceptable in other nations. The use of non-FDA approved therapies in the USA should be based on solid data support, and on informed consent to the patient. As an added benefit of combination therapy, adverse effects associated with high drug doses may be mitigated due to the requirement for lower dosages of each individual agent $(15,16,119)$. Numerous clinical studies have evaluated the safety and efficacy of combi- 
nation therapy; research findings support combination therapy with opioids (morphine or hydromorphone) and bupivacaine; morphine and clonidine; and morphine and ziconotide $(6,7,15,17,18,109,120-122)$.

Clinical research also suggests that dose escalation and subsequent increases in concentration can prompt the development of IT granulomas. With $63.9 \%$ of clinicians reporting in an online survey that they had treated at least one patient who developed a cathetertip inflammatory mass, IT granulomas are becoming a more common consequence of IT therapy (19). A review by Hassenbusch et al (123) of published and unpublished case reports found that IT granulomas only occurred in patients who received IT opioid monotherapy, IT combination therapy, or who were administered agents not approved for long-term IT use (64). With the exception of sufentanil, ziconotide, and fentanyl, all agents used in implantable devices have been associated with the development of inflammatory masses (6). The issue with baclofen is unclear at present. The results of IT granuloma development can be severe and may cause long-term neurologic damage and permanent paralysis if not properly managed (13). Therefore, clinicians should vigilantly monitor patients for loss of analgesic effect accompanied by new and progressive neurologic symptoms, both of which are primary indications of granuloma development. Early detection requires a low threshold to perform a catheter evaluation and radiographic work-up, typically an MRI with gadolinium. Careful monitoring will ensure timely diagnosis and may increase the likelihood that minimally invasive therapy-rather than surgical removal of the masswill be sufficient to resolve the problem. This appears to be less problematic in the cancer and other end-of-life patients because of the reduced time of therapy (123).

Not only does the sequela of long term opioid use continue to be a concern with intrathecal therapy, but so too is withdrawal. When catheter disruption, battery failure, or human error causes abrupt cessation of high-dose IT therapy, severe and potentially fatal consequences can occur, and although not typical for opioid medications, can occur with other IT therapy. For example, abrupt cessation of IT baclofen can be lifethreatening and has been associated with severe consequences, including respiratory depression, hyperthermia, disseminated intravascular coagulation, and acute multiorgan failure $(13,108,109)$. Sudden disruption or discontinuation of high doses of clonidine can also have detrimental effects, resulting in rebound hypertension and an increased risk for stroke $(4,6,13,108,109)$.
If abrupt cessation of these agents is unavoidable, systemic dosing should be initiated immediately to prevent withdrawal syndrome. Notably, there are no reports of withdrawal syndrome from ziconotide or bupivacaine (20). In addition, revision and restarting a revised IT system requires care to avoid overdosing, which is a primary cause of morbidity and mortality with intrathecal therapies (115).

\subsection{Patient Selection Guidelines}

Implantable drug delivery systems offer an effective therapeutic intervention for many patients at the end of life; however, clinicians must also consider the possible implications of therapy prior to proceeding with device implantation.

\subsection{Diagnosis and Pain Characteristics}

Theoretically, to maximize the results of IT therapy, including appropriate medication selection or site of catheter placement, implantation requires careful anatomic consideration of the nociceptive and/ or neuropathic factors responsible for the pain condition. Although the type of cancer can greatly influence therapeutic outcomes (21), there is no robust evidence indicating which pain type is best suited for treatment with an implantable device (21). Patients diagnosed with soft tissue cancers (e.g., pancreatic cancer, liver/ lung cancer) often present with visceral nociceptive pain and can be effectively treated with IT opioid therapy (21). Similarly, somatic nociceptive pain commonly attributed to bone metastases is typically responsive to IT opioid therapy, especially when morphine is administered (21). Strong evidence also exists that suggests that IT drug delivery provides improvement in neuropathic pain, often associated with postherpetic neuralgia or cancer-related plexopathies that alter the structure or function of nerves $(21,108,109)$. Patients presenting with a combination of mixed nociceptive/neuropathic pain are frequently the most challenging to treat and may require the use of combination therapy to achieve effective analgesia $(6,7,21,22)$.

Obtaining an accurate measure of pain intensity is also a critical part of the diagnostic evaluation (21). An accurate measure of pain intensity-as quantified through use of numerical pain rating scales, visual analog scales, verbal rating scales, faces pain rating scales, and/or pain questionnaires $(21,22,)_{\text {-is impor- }}$ tant during both the patient selection process and as treatment progresses. Such measures serve as a baseline measurement from which to determine the 
continuing effect of therapy. Emphasizing the importance of assessing pain intensity, the majority of clinical trials to evaluate IT therapy utilize pain severity as an inclusion criterion and means of comparing efficacy data among trial participants. Pain intensity also has an important impact on treatment outcomes; although patients with greater pain severity may achieve a reduction in pain level via IT drug delivery, the overall pain intensity may remain high compared with individuals who present with a lesser magnitude of initial pain (113). It is also essential to consider that pain assessment in the patient with advanced cancer can often be confounded by delirium, either related to the opioids or related to their overall medical condition (41); acknowledging such influences throughout the patient evaluation is necessary to accurately assess pain severity and the magnitude of pain relief following treatment.

Once IT therapy is initiated, patients may still experience breakthrough pain, and immediate-release oral opioids or enabling patient-controlled intrathecal bolusing $(8,21)$ may be used to alleviate severe breakthrough pain and maintain quality of life.

\subsubsection{Panel Recommendations}

Pain intensity should be considered before, at the onset, and throughout intrathecal therapy, and along with objective and subjective quality of life measures, provides a useful measure to employ when initiating and titrating therapy.

\subsection{Prior Therapy and Its Results}

The pain treatment continuum for cancer-related pain begins with the most conservative option available, typically nonopioid analgesics, weak opioids, and oral/topical opioids, and introduces stronger opioids and adjuvant medications as necessary (21-25,122-126). This step-wise strategy, as outlined by the World Health Organization 3-step analgesic ladder, is thought to adequately provide effective pain relief for an estimated $80 \%$ to $90 \%$ of cancer pain patients; yet this leaves a small, but significant, number of patients who require a more aggressive therapeutic intervention (8,127-133). Careful patient selection, with consideration of past treatment regimens and their results, may provide insight into the potential effect of IT therapy in patients unable to achieve adequate relief with standard medical management.

A number of complications related to intrathecal therapy have been widely published $(21,122,130)$. In addition to causing side effects, intrathecal opioids can prompt increased CNS stimulation; higher opioid doses may also result in greater sensitivity to pain (122).

Studies have evaluated the efficacy of IT therapy versus comprehensive medical management (CMM), and have largely found intraspinal drug delivery to provide superior relief compared with standard medical management $(4,15)$. A 4-week randomized clinical trial by Smith et al (4) found that $84.5 \%$ of patients who received an implantable drug delivery system in addition to CMM achieved clinical success-defined as pain control combined with change of toxicity-compared to $70.8 \%$ of patients receiving CMM alone ( $n=143 ; P=.05)$ (4). Patients in the IT therapy cohort also reported greater improvements in fatigue, depressed level of consciousness, and survival (4). A follow-up study demonstrated sustained effects with IT therapy out to 6 months, suggesting that patients who fail to respond to traditional pain management may benefit from therapy with an implantable drug delivery system (4).

There are no robust data that show a precise linear correlation between response to systemic opioids and results of IT therapy. However, clinical experience with cancer-related pain treatment suggests that patients with a history of poor pain relief or intolerability to systemic opioids can effectively manage pain with IT therapy $(6,19)$. This improved efficacy is likely due to the fact that IT agents are applied near the site of action at the spinal dorsal horn $(132,133)$. The use of polyanalgesia may further improve outcomes in this complex patient group (6).

\subsubsection{Panel Recommendation}

The panel recommends a stepped approach to therapy for patients with intractable cancer-related pain, beginning with the most conservative therapeutic options and progressing to more aggressive regimens when analgesia is inadequate or adverse effects are intolerable. IT therapy may also be applicable for patients having difficulty with medication management or for those with comorbid conditions, such as morbid obesity or sleep apnea, which increase the risk of oral opioid-related adverse effects $(6,134)$.

Although it is probable that patients who previously obtained a $50 \%$ or greater reduction in pain with systemic opioids will benefit from IT therapy, randomized controlled trials have not yet confirmed a direct association between a patient's response to oral opioids and ensuing response to IT therapy (135). 


\subsection{Associated Medical Comorbidities}

Patients at the end of life, whether due to cancer or other illness, often have coexisting medical conditions that influence the selection of both disease treatment and pain management options (125). In addition to treatment for preexisting comorbidities, cancer patients are also likely to undergo concurrent chemotherapy and/or radiation. To maximize the effect of treatment without compromising patient safety, all pre-existing comorbid conditions must be evaluated for potential contraindications to IT therapy (136).

\subsection{Concurrent Chemotherapy/Radiation Treatment}

Implantation of an IT drug delivery device is a reasonable therapeutic option in patients undergoing concomitant chemotherapy or radiation, as findings from a study by Smith et al (4) suggest that IT therapy is associated with better analgesia and fewer adverse effects compared with conventional pain management options (8).

\subsubsection{Panel Recommendations}

In general, the initiation or continuation of IT therapy is unlikely to interfere with the effects of chemotherapy; yet, some factors warrant further consideration to ensure patient safety. Panel consensus acknowledges that a white blood cell count $\leq 2 \times 10^{9} / \mathrm{L}$ and/or an absolute neutrophil count $\leq 1,000 / \mu \mathrm{L}$ may constitute a contraindication for implantation of an IT device (8); notably, patients with a white blood cell count $\leq 1.5 \times 10^{\%} / \mathrm{L}$ can be considered for the procedure provided they are receiving growth factor treatment (8). Pragmatically, the pump implant can be scheduled between count nadirs associated with chemotherapy.

Similar to neutrophil count nadirs, potential complications associated with platelet count nadirs following chemotherapy regimens can be avoided by scheduling surgery in coordination with the oncologist. Traditionally, surgery is deemed permissible provided a patient's platelet count exceeds $50,000 / \mu \mathrm{L}$; yet, a more cautious approach is sometimes recommended during neurosurgical procedures, such that patients should be able to maintain a platelet count between 70,000 and $100,000 / \mu \mathrm{L}$ (137). Nonetheless, the panel concedes that the decision to proceed with device implantation should be made in accordance with the oncologist, rather than be based on platelet counts alone. Consultation with the oncologist is also critical to prevent other surgical complications, as certain newer chemotherapies can re- sult in excessive bleeding; bevacizumab, for example, is known to cause coagulopathy out to nearly one month following administration (138).

\subsection{Radiation and Intrathecal Drug Delivery}

Although there is no evidence regarding the limits of radiation exposure on IT pumps, battery drain or electric failure of the implanted device can occur if the pump is directly within the radiation field (8).

\subsubsection{Panel Recommendations}

To mitigate these possibilities, the panel recommends moving the radiation source, shielding the implanted system with lead, and/or minimizing overall radiation exposure; pump relocation should be considered if the device is located directly in the field (8). Further, vigilant and conscientious interrogation of the pump is advocated when radiation exposure is known or suspected to ensure correct drug delivery.

\subsection{Metastatic Disease Involving the Neuraxis}

Chronic pain is a common feature of many metastatic disease states involving the neuraxis. Nearly all cancer patients diagnosed with epidural metastases experience severe pain, with more than $60 \%$ of patients in this population reporting back pain (118). Although not an absolute contraindication, epidural metastases may negatively impact the efficacy and complication rates of intraspinal pain treatment $(23,126)$. Epidural metastases associated with spinal stenosis may impede the diffusion of intraspinal pain medication by inhibiting diffusion to the nerve roots and spinal cord (126). A retrospective analysis of 201 patients with cancer pain who received IT therapy found that the presence of epidural metastases increased complications associated with catheter insertion and the need for daily opioid doses; adverse events also increased when the epidural metastases caused full or partial spinal stenosis (23). The researchers concluded that the relation of the epidural tumor to the puncture site, catheter length, and degree of spinal stenosis affects the occurrence and severity of catheter insertion complications (23).

\subsubsection{Panel Recommendations}

In accordance with these findings, the panel recommends careful consideration of the location of metastatic disease before proceeding with device implantation. Tumor bleeding during catheter placement leading to neurologic compromise is a theoretic concern. 


\subsection{Immunocompromised Patients}

The safety and efficacy of IT therapy has been evaluated in the setting of advanced medical illness and conditions involving significant immunocompromise, including cancer and AIDS $(3,139)$. Although research does not reveal whether IT therapy failure due to device infection is independently increased by immunosuppression, indirect comparative data suggest that device infection rates for immunocompromised patients and all treated individuals are similar $(3,4,24)$.

\subsubsection{Panel Recommendations}

The panel recommends that IT therapy is a useful strategy for immunocompromised patients and success hinges on patient preparation and mitigation of infection reduction during trialing and implantation. Further, as IT opioids have been shown to compromise immunologic function, careful titration and medication selection (including nonopioid medications) are required.

\subsection{Infection}

\subsubsection{Chronic Infection}

Active infection with systemic signs is considered to be an absolute contraindication to any device implantation $(25,140)$. Clinicians are advised to consult with an infectious diseases specialist to obtain information about patient-specific safety concerns to further minimize the potential for device-related infection (8).

\subsubsection{Surgical Site Infection (SSI) Prophylaxis}

The Centers for Disease Control and Prevention (CDC) provide guideline statements regarding strategies to reduce surgical site infections (SSI), including suggestions on surgeon, patient, and environmental mitigating factors (141). Only appropriate antibiotics administered within 30 minutes of incision, low pressure irrigation, and surgical chlorohexidine prep are supported by conclusive evidence (141). Although postoperative antibiotics, pre-op chlorohexidine bathings, and post-op antiobiotic ointment have no supportive evidence, they continue to be employed. Despite these efforts, wound infection is the most frequent devicerelated complication of drug delivery system implantation (24).

\subsubsection{Panel Recommendations}

Infection can be a devastating complication of any surgical procedure, including IT therapy. The panel rec- ommends that patients with systemic signs of infection should not be implanted. Further, SSI prophylaxis and appropriate antibiotic use is advocated. Further, close perioperative monitoring of wound healing and aggressive treatment of infection is recommended by the panel to reduce morbidity (142).

\subsection{Coagulopathies and Anticoagulant Therapy}

Anticoagulant and antiplatelet therapy have become a routine aspect of medical management for a variety of disease states. Many cancer patients receive ongoing anticoagulation therapy, as venous thromboembolism is a leading cause of mortality in this patient population (143). Unless patients are able to discontinue the use of, or appropriately bridge anticoagulants prior to surgery, intrathecal procedures should be avoided due to elevated neurologic complication risk (144). Despite the relative rarity of spinal hematoma (with estimated incidence rates of 1:220,000 and 1:150,000 following IT and epidural instrumentation, respectively), this complication is responsible for nearly half of all reported spinal cord injuries; during the 1990s spinal hematomas were the primary source of malpractice claims in the American Society of Anesthesiologists Closed Claims database $(144,145)$.

The Joint Commission designates anticoagulants as 1 of 5 leading classes of drugs that contribute to avoidable adverse events in US patients (146). The introduction of low-molecular-weight heparin (LMWH) led to case reports of catastrophic neural injuries and epidural hematomas resulting from neuraxial blockade (typically epidural anesthesia) (144). As a result, the US Food and Drug Administration (FDA) added a black box warning to LMWH drug labels that cautions clinicians against using neuraxial anesthesia in patients receiving LMWH $(140,146)$. Since then, the American Society of Regional Anesthesia and Pain Medicine (ASRA) has systematically reviewed elevated bleeding risk associated with various anticoagulant and antiplatelet agents (Table 3 ) $(13,144)$.

\subsubsection{Panel Recommendations}

The panel recommends that clinicians follow the evidence-based ASRA guidelines in the selection of patients for implantation with an IT drug delivery system, and as clearly defined in the consensus statement, when managed appropriately, the chronic use of anticoagulants are not a contraindication to intrathecal drug implantation. In lieu of the comorbidities requir- 
Table 3. Recommendations for neuraxial anesthesia in patients receiving thromboprophylaxis

\begin{tabular}{|c|c|c|}
\hline Drug or Drug Class & Bleeding Risk & Recommendation \\
\hline Unfractionated heparin & $\begin{array}{l}\text { No increased risk with neuraxial } \\
\text { blockade; risk of heparin-induced thrombocy- } \\
\text { topenia with administration for } \geq 4 \text { days }\end{array}$ & $\begin{array}{l}\text { Subcutaneous heparin ( } 5000 \text { units every } 12 \\
\text { hours) for DVT prophylaxis; remove indwelling } \\
\text { neuraxial catheters } 2-4 \text { hours after last heparin } \\
\text { dose }\end{array}$ \\
\hline LMWHs & $\begin{array}{l}\text { Moderate risk with single daily dose for DVT } \\
\text { or PE treatment and thromboprophylaxis; high } \\
\text { risk with combination of antiplatelet or oral } \\
\text { anticoagulant medications }\end{array}$ & $\begin{array}{l}\text { LMWHs should be held } 24 \text { hours before surgery } \\
\text { and resumed 8-12 hours postoperatively; con- } \\
\text { sider placement of an inferior vena cava filter } \\
\text { before surgery for patients at high risk for PE; } \\
\text { oral anticoagulants may be restarted } 12 \text { hours } \\
\text { after surgery }\end{array}$ \\
\hline Warfarin & $\begin{array}{l}\text { Spinal puncture and lumbar blockade contrain- } \\
\text { dicated; high risk with combination of LMWH, } \\
\text { heparin, or antiplatelet medications }\end{array}$ & $\begin{array}{l}\text { Discontinue } 4-5 \text { days before surgery; INR must } \\
\text { be }<1.5 \text { before surgery; warfarin } 5 \mathrm{mg} \text { can be } \\
\text { resumed immediately after surgery and adjusted } \\
\text { to INR of } 2.0-3.0\end{array}$ \\
\hline NSAIDs & $\begin{array}{l}\text { No significant increase in risk as } \\
\text { monotherapy; high risk with } \\
\text { combination of anticoagulant or } \\
\text { antiplatelet medications }\end{array}$ & $\begin{array}{l}\text { No specific recommendations; switch to COX- } 2 \\
\text { inhibitor for patients requiring anti-inflamma- } \\
\text { tory therapy }\end{array}$ \\
\hline Ticlopidine, clopidogrel & $\begin{array}{l}\text { Risk based on history of easy bruising, excessive } \\
\text { bleeding, female sex, and increased age; in- } \\
\text { creased risk with combination of anticoagulant } \\
\text { or antiplatelet medications }\end{array}$ & $\begin{array}{l}\text { Discontinue ticlopidine } 14 \text { days before neuraxial } \\
\text { blockade; discontinue clopidogrel } 7 \text { days } \\
\text { before neuraxial blockade }\end{array}$ \\
\hline Platelet glycoprotein IIb/IIIa antagonists & $\begin{array}{l}\text { Contraindicated within } 4 \text { weeks of surgery; } \\
\text { profound effect on platelet aggregation }\end{array}$ & $\begin{array}{l}\text { Avoid neuraxial techniques until platelet func- } \\
\text { tion has recovered; neurologic monitoring after } \\
\text { postoperative administration resumes }\end{array}$ \\
\hline
\end{tabular}

DVT = deep vein thrombosis; $\mathrm{PE}=$ pulmonary embolism; LMWHs = low-molecular-weight heparins; INR = international normalized ratio; COX-2 = cyclooxygenase- 2 ; NSAIDs = nonsteroidal anti-inflammatory drugs.

Originally published in Ghafoor VL, Epshteyn M, Carlson GH, Terhaar DM, Charry O, Phelps PK. Intrathecal drug therapy for long-term pain management. Am J Health Syst Pharm 2007; 64:2447-2461. @2007, American Society of Health-System Pharmacists, Inc. Reprinted with permission. (13)

ing anticoagulation and the consequence of normalization, the panel recommends consulting the prescribing physician prior to discontinuation (34).

\subsection{Diabetes Mellitus}

In 2007, 23.6 million individuals had diabetes, constituting approximately $8 \%$ of the US population; an additional 57 million patients were considered prediabetic, as indicated by elevated blood glucose levels (147). Estimates show that two-thirds of individuals with diabetes experience severe systemic complications, such as peripheral neuropathy, poor glucose control, increased cancer risks, obesity, and/or hypertension $(148,149)$.

No evidence exists to clarify IT drug therapy's role in treating chronic diabetes-related pain, nor have studies examined the associated risks of treating patients with diabetes compared with those without this disease. Yet, data confirm the association between diabetes and poor wound healing and surgical site infections (150). Furthermore, research confirms that surgical patients with lower preoperative hemoglobin A1c levels experience fewer surgical site infection, morbidity, and mortality rates (151).

\subsubsection{Panel Recommendations}

The panel recommends that diabetes mellitus be managed with tight control perioperatively (147-151), with vigilance for perioperative surgical site infections.

\subsection{Obesity-Related Obstructive Sleep Apnea}

Data obtained between 2005 and 2006 found that approximately one-third of US adults were obese, indicating that obesity represents a significant public health epidemic in this country (152). Among other medical implications, individuals who are obese are predisposed to developing obstructive sleep apnea (OSA) due to changes in anatomy that cause upper-airway ob- 
struction during normal sleep. More than 18 million US adults suffer from OSA (153), the consequences of which include chronic carbon dioxide retention and pulmonary hypertension. An observational study by Webster et al (154) found that $75 \%$ of participants treated with chronic opioid therapy had sleep-disordered breathing; $39 \%$ also presented with OSA $(n=147)$ (134). Findings from overnight polysomnographies indicated that opioids might have contributed to the incidence of sleeprelated apnea in these patients (154). Farney et al (134) also evaluated the relationship between chronic opioid use and respiratory complications, describing 3 case reports of respiratory adverse events related to long-term sustained-release opioid use. The researchers compared the effects of opioid therapy with common respiratory problems experienced by opioid-naïve OSA patients and found that opioid use was associated with several respiratory exacerbations, including increased apnea duration and hypoxia severity during non-rapid eye movement (NREM) sleep; ataxia with irregular respiratory pauses during NREM sleep; and severe hypoxemia (134). These concerns should be considered in the endof-life patient with sleep apnea.

Although updated guidelines recently published by the American Society of Anesthesiologists offer recommendations regarding the administration of neuraxial opioids to potentially high-risk patients, such as those at risk for respiratory depression, (155) were intended for acute pain management, they may apply to the treatment of chronic pain as well. The guidelines conclude that patients with OSA may receive continuous IT opioids, although adequate monitoring for adverse effects throughout the administration period is crucial (Table 4) $(8,155)$.

Table 4. Early detection of respiratory depression following opioid administration: practice recommendations

- Careful monitoring for adequacy of ventilation, oxygenation, and level of consciousness is essential for all patients

- During the first 12 hours following opioid administration, monitoring should occur at least once.

- Thereafter, monitoring should occur at least once every 2 hours for 12 hours.

- Monitoring should occur every 4 hours for at least 48

hours, 24 hours after administration.

- For high-risk patients (e.g., those with obesity and/or sleep apnea), increased monitoring is warranted.
IT ziconotide monotherapy may offer clinical advantages when treating patients prone to respiratory complications (20). Therefore, provided all other patient selection criteria are met, patients with OSA may be considered for treatment with a drug delivery system, and in many cases the use of IT drugs may help mitigate the risks of death from oral opioids in this group.

\subsubsection{Panel Recommendations}

Caution must be exercised when employing IT opioid therapy in patients with existing pulmonary compromise. Appropriate dose reduction, monitoring and vigilance is warranted for signs of opioid-induced respiratory depression.

\subsection{Geriatric Population}

The prevalence of cancer in the aged population is high with patients in this age group accounting for $60 \%$ of newly diagnosed cancers and $70 \%$ of all cancerrelated deaths as well as a high percentage of undertreated pain (156-158). A retrospective record review of 537 elderly hospice patients with terminal cancer, for example, found that $44 \%$ of respondents reported pain ranging in severity from discomfort to excruciating (159).

Older patients typically exhibit greater responsiveness and lower development of tolerance to opioids, suggesting an age-dependent effect with chronic administration (160). Nevertheless, because both comorbidities and polypharmacy are common in the elderly, opioid use in this population should be approached with caution $(156,161)$. Still another consideration is the effect of opioid therapy in the context of cognitive impairment-a condition often present in elderly patients-given that opioids can cause thought process disturbance, and may make diagnosing the cause of dementia more complex (156). Cognitive impairment can also make it difficult for geriatric patients to describe their pain experience and/or communicate adverse effects, the results of which are often undertreatment or overtreatment (156). Finally, an array of other adverse effects secondary to opioid therapy, including dizziness and respiratory depression, can increase the already elevated fall/fracture risk in this population (156).

The aged population is not considered an absolute contraindication to IT therapy. Patient selection requires a keen understanding of geriatric medicine and mindful eye on preexisting comorbidites. Identified co- 
morbidities should be diagnosed and treated according to established standards of care prior to implanting a drug delivery system. Finally, when prescribing IT opioids, providers must carefully monitor the patient for adverse therapeutic effects. The panel also notes that nonopioid IT therapy is an appropriate alternative to opioid administration.

\subsubsection{Panel Recommendations}

As intraspinal drug delivery can effectively mitigate pain in patients at the end of life, the panel does not designate any preexisting medical condition as an absolute contraindication for IT therapy.

\subsection{Psychological Evaluation in Cancer-related Pain}

\section{Psychological Evaluation}

The diagnosis of cancer, its associated pain and treatment options, can result in a variety of emotional reactions and fears, including the fear of loss of bodily functions, disfigurement, loss of autonomy and independence, abandonment and isolation, becoming a burden, and financial impact. Few concerns generate more distress than the fear of uncontrolled pain and end-of-life issues. Caregiver reactions can also inflame or moderate those of the patient.

Persistent pain, regardless of its associated physical pathology (e.g., malignant tumor, degenerative disc disease, or osteoarthritis), is multidimensional influenced by psychosocial factors. These psychosocial factors can impact the outcomes of pain-relief oriented somatic therapies. Co-utilization of behavior/psychological interventions can enhance pain relief. Although some $62 \%$ of adults with cancer are disease-free 5 years after diagnosis (162), recurrence rates vary and are frequently associated with the re-emergence of pain. By virtue of this uncertainty, patients often exhibit a significant amount of somatic vigilance and preoccupation, which can lead to an over-interpretation of even minor physical symptoms and heightened psychological distress (163).

Pain occurs in most types of cancer. For example, an estimated $30 \%$ of women with metastatic breast disease report phantom breast pain following mastectomy (164).

Cancer-related pain has many unique features, including the need for patients to understand that their condition is potentially fatal. Pain is often seen as an inevitable and frequently untreatable aspect of can- cer therapy, as some patients interpreted it as a sign of disease progression. Those interpreting their disease as punishment are likely to manifest higher levels of pain and depression (165).

The role of psychological factors and emotional stresses may be difficult to overstate.

Psychological factors, including anxiety, expectations, cognitive appraisals, self-efficacy, and perceived control, influence the reports and experience of physiological processes, fatigue, sleep, appetite nausea, and pain. Spiegel and Bloom (166) noted that mood and the interpretation of pain predicted patients' reported pain intensity in 86 metastatic breast cancer patients. Furthermore, some did not experience pain until they were informed of their diagnosis (166). Ahles et al (167) reported that $61 \%$ of patients were afraid that pain or changes in pain signified a progression of their disease.

A review of the literature found that nearly $73 \%$ of patients reported an association between pain and psychological distress (168-176). Increased pain has also been associated with greater mood disturbance (169). A strong correlation was found between pain and the presence of anxiety and depression in terminally ill patients (170) and those with pancreatic cancer (171). Indeed, Kelsen et al (171) noted that a reduction in depression to be associated with pain relief. Depressed mood is often a natural reaction and should be distinguished from the presence of a depressive illness, which may be preexisting and exacerbated by the cancer and/ or related pain. Indeed, severe cancer pain has been known to reactivate prior emotional trauma and its associated depression (172). Severe forms of depression complicate the management of pain, can influence a patient's motivation, impact compliance, and stimulate death wishes and/or suicidality (173). Importantly, this degree of depression is not always acknowledged by the patient as Rathbone et al (174) noted that $58 \%$ of patients did not divulge certain symptoms to the health care professional and $52 \%$ omitted complaints involving psychosocial problems.

The Hospital Anxiety and Depression Scale (HADS) (177) has been a useful and efficient instrument for detecting depression in cancer patients. Monroe (173) has outlined a variety of interview questions, which can aid in uncovering mood disturbances. Cancer-related pain can also lead to maladaptive coping, feelings of hopelessness and helplessness, and anhedonia resulting in withdrawal from day-to-day activities which in turn contributes to mood disturbances. The Brief Pain Inventory (178), Karnofsky Index (179), and Short-Form 
Health Survey (SF-12) (180) have been useful in assessing functioning and pain-interference levels among cancer pain patients.

HADS, Spielberger's State Trait Anxiety Inventory (STAI), and Hamilton Rating Scale for Anxiety (181) have been used to assess levels of anxiety, which commonly coexist with depression. Anxiety can lower the pain threshold and interfere with disclosure and problem resolution. Presenting as generalized anxiety or taking the form of a phobic disorder or panic attacks, anxiety disorders include post-traumatic stress disorder (PTSD), acute-stress response, generalized anxiety disorder, obsessive-compulsive disorder, pain disorder, and phobias. They occur in about $7 \%$ to $18 \%$ of the general population, $20 \%$ to $40 \%$ of chronic pain patients, and $13 \%$ to $16 \%$ of cancer patients, with $4 \%$ of cancer patients having a preexisting anxiety disorder. Precancer psychiatric disorders are associated with increased cancer-related distress. It is estimated that between $14 \%$ and $38 \%$ of women with breast cancer develop a psychiatric disorder after the diagnosis of cancer or at the time of a recurrence $(182,183)$. The presence of PTSD at all stages in cancers of mixed etiology is $3 \%$ to $19 \%$ (172). Patients manifesting anxiety sensitivity, i.e., the fear of feeling the physical manifestations of anxiety, often misinterpret innocuous bodily sensation as threatening or indicative of disease progression $(184,185)$. Anxiety tends to peak at specific points, including initial diagnosis, initiation of cancer treatment, cancer recurrence, failure of treatment, and perception of dying (186).

Although pain reduction has been associated with improved emotional factors, it may have its own psychological "side effects," resulting in a distraction from other issues. For example, Cahana (187) reports on 2 patients with cancer-related pain treated by IT therapy. Both patients demonstrated a reduction of $50 \%$ or greater in pain intensity, increased cognitive function, and increased daily activity. However, there was an unexpected concomitant increase in depression, anxiety, conjugal conflicts, interpersonal disputes (e.g., regarding previous marital stressors, ex-spouses, children, inlaws), and the emotional burden of cancer and death along with decreased well-being.

Unfortunately, there are many barriers to effective treatment of cancer-related pain. Some are patient-related and others are caregiver-related. Patient-related barriers include fear of addiction, pharmacologic tolerance, treatment of side effects, interpreting pain as a sign of disease progression, fear of distracting the physician from treating the disease, fear of injections, fatal- ism, and the belief that "good" patients do not complain $(188,189)$. Patients harbor the fear their reported pain will be interpreted as psychological. They may also hesitate to fully disclose their residual pain for fear of disappointing their physician. These and other fears are higher among the older and less educated patients and those from the lower socioeconomic strata. Caregiverrelated barriers included end-of-life issues, side effects, addiction, fear of injections, and that increased pain equates to increased disease.

\subsection{Panel Recommendations}

A pre-implantation psychological evaluation is carried out in approximately $11 \%$ of cases with cancerrelated pain, compared with $89 \%$ for noncancer pain (190). Whereas psychological evaluations with noncancer pain patients tend to focus on trait-related characteristics, such as personality and degree of disability, that of the cancer-related pain patient may need to address state-related characteristics. By virtue of the uncertain course of the disease (i.e., cure, disease progression, improvement followed by recurrence) and unclear longevity of IT therapy, periodic brief psychological evaluations may be needed to re-evaluate the potential need for adjunctive psychological therapies (191). Cancer survivors with chronic pain should also be considered for IT therapy. Many of the same issues involved with noncancer pain patient selection would apply in these patients (192). To better describe the suggested psychological evaluation focus, it is useful to consider cancer-related pain in 3 different categories with the need for a psychological evaluation/therapy based on the status of the patient's disease (Table 5).

Category 1: Patients whose life expectancy is significantly compromised and the goal of therapy is palliation. A pretrial/internalization psychological evaluation should be considered optional. It should be done at the discretion of the physician, with a focus on identifying cancer- and/or pain-related psychological factors potentially amenable to psychological interventions that may facilitate patient adjustment and analgesia rather than to clear the patient psychologically for IT therapy.

Category 2: Patients whose disease process has been arrested, but wherein there is a significant probability of recurrence. A psychological evaluation is encouraged with an emphasis on periodic psychological consultation/intervention to assist with changes in disease process/recurrence and coping.

Category 3: Patients whose cancer has been eradicated but who have residual chronic pain secondary to 
the medical treatment and/or anatomic or physiological disease related damage. These patients should undergo a psychological evaluation in much the same way as those with chronic noncancer pain. Whenever possible, the primary caregiver should be included to assess the type and degree of support.

\subsection{Social Issues and Health Care Coverage}

When implanting a patient at the end of life with an intrathecal pump, it is important that proper social support exists for the procedure and the follow-up care (126). The support system also plays a pivotal role in ensuring the patient has access to physicians for management of the infusion and is able to comply with medication refill schedules. With disease progression, refills may be required more often, as IT doses are adjusted every few days, or in some cases, on a daily basis (8). In addition, combination IT therapies may need to be frequently changed to match the patient's need. Ideal candidates for IT drug delivery system implantation are able to maintain refills schedules, and typically are patients who do not have cognitive, psychological, or socioeconomic barriers-and perhaps most importantlyare those who benefit from family or friend support.

Issues of insurance coverage are further complicated as a patient nears the end of life. For example, patients who are transferred to a hospice facility for palliative care may have difficulty obtaining pump refills. Although hospice organizations are typically responsible for all treatment costs, once a patient is transferred, the hospice is often reluctant to cover IT pump refills. Instead, patients who are stable enough to travel would need an individual from their social support sys- tem to transport them to the clinic, where depending on the payer, medication refills may be covered. If a patient is in a skilled nursing facility (SNF), then the cost of a pump refill is borne by the SNF provided the refill is performed at the SNF site. Sometimes there is resistance by the SNF to provide this service. If the patient is stable enough to be transported to the clinic, then the refill cost can usually be billed to Medicare. Other insurers may have similar restrictions but it depends on the payer, and the provider will need to assess with the primary and secondary payer on coverage benefits. Similarly, availability and coverage of drug compounding must also be considered. Not all patients will have access to this service and some insurance providers may restrict use of commercially available drugs, which will have a major influence on the agents used and refill intervals.

\subsection{Panel Recommendation}

A patient's access to medical care, both pre- and post-implantation, is paramount to ensuring successful treatment with IT therapy. Lack of insurance coverage and/or the lack of a strong social support system capable of assisting the patient in accessing treatment represent relatively strong contraindications to device implantation.

\subsection{Technical Factors}

\subsection{Spinal and Anatomic Considerations}

A critical factor in optimizing clinical outcomes for cancer and end-of-life patients is ensuring safe and efficient access to the spinal region during device implantation (193). Individual patient circumstances such as disease pathology, medical characteristics, and varia-

Table 5. Recommendations for cancer pain patients based on disease status

\begin{tabular}{||c|l|l||}
\hline & \multicolumn{1}{|c|}{ Patient Characteristics } & \multicolumn{1}{c|}{ Recommendation } \\
\hline Patient Category 1 & $\begin{array}{l}\text { Comprises those patients whose life expec- } \\
\text { tancy is significantly compromised by their } \\
\text { disease and the goal of therapy is palliation }\end{array}$ & $\begin{array}{l}\text { A pretrial/internalization psychological evaluation should be con- } \\
\text { sidered optional. It should be done at the discretion of the physician, } \\
\text { with a focus on identifying cancer- and/or pain-related psychologi- } \\
\text { cal factors potentially amenable to psychological intervention that } \\
\text { may facilitate patient adjustment and analgesia rather than to clear } \\
\text { the patient psychologically for IT therapy. }\end{array}$ \\
\hline Patient Category 2 & $\begin{array}{l}\text { Consists of patients whose disease process has } \\
\text { been arrested, but wherein there is a signifi- } \\
\text { cant probability of recurrence. }\end{array}$ & $\begin{array}{l}\text { A pretrial/internalization psychological evaluation is encouraged, } \\
\text { with an emphasis on periodic psychological consultation/interven- } \\
\text { tion to assist with changes in disease process/recurrence and coping }\end{array}$ \\
\hline Patient Category 3 & $\begin{array}{l}\text { Comprises patients whose cancer has been } \\
\text { eradicated by surgery or other therapies, but } \\
\text { who have residual chronic pain secondary } \\
\text { to the medical treatment and/or anatomic or } \\
\text { physiological disease related damage. }\end{array}$ & $\begin{array}{l}\text { Patients should undergo a pretrial/internalization psychological } \\
\text { evaluation, approached in much the same way as those with chronic } \\
\text { noncancer pain. Whenever possible, the primary caregiver should } \\
\text { be included to assess the type and degree of support }\end{array}$ \\
\hline
\end{tabular}


tions in spinal anatomy can complicate the procedure, particularly when inserting the catheter at the L2-3 or L3-4 level (194).

To avoid compromising sterility and patient safety, determination of patient positioning during surgical implantation should consider the presence of metastatic involvement or occult pathology in the spinal column (25), arthritis in the joints, paraplegia, spasticity, or scoliosis (193). Clinicians should also be mindful that anatomic abnormalities may obscure the location of the pressure gradient between the epidural space and spinal fluid (193). Fluoroscopy may be used to compensate for residual anatomic tilt (193). Similarly, alternative methods for directing the catheter to the IT space for final tip placement may also need to be reevaluated based on anatomic variation. This may require entering the cerebrospinal fluid (CSF) above the level of L1 (193).

Finally, anatomic factors such as arterial blood supply, CSF bulk flow, and diffusion through the dura and meninges can affect the uptake and delivery of IT agents, thereby influencing therapeutic outcomes. Metastatic lesions can cause occlusion and impede normal CSF flow. Nerve root size and volume disparities previously described can also influence drug delivery response (193).

\subsubsection{Panel Recommendations}

A thorough understanding of the patient's anatomy and potential complicating confounders is vital to developing a cogent operative plan. Accordingly, the clinician must carefully be proactive preoperatively to identify appropriate surgical technique and ideal device placement (193).

\subsection{Device-Related Limitations}

When evaluating a patient for IT therapy, it is important to be aware of several technical concerns related to device implantation. The primary concern for IT pumps is size; it is necessary to consider the subcutaneous position and route the tunneled catheter will require during surgical placement. Clinicians should ensure that the patient is fully aware of both the size and the location of the proposed pump pocket prior to the procedure and then mark the agreed-upon site while the patient is in the sitting position. The left- or rightlower quadrant of the abdomen is likely to be the most suitable location for device placement because of the large size of most IT pumps (34), although higher placement may be necessary in patients with an overhanging panniculus. To avoid ongoing pain caused by pump contact with internal body structures, clinicians should avoid placing the pump in close proximity to the anterior rib or iliac crest (34). Implant site depth is largely based on ensuring pump accessibility for required refills, although it may vary somewhat based on patient weight (34). Other factors to consider when designating pump placement include the presence of extensive scarring resulting from previous abdominal surgery, as well as a colostomy or other enterocutaneous ostomy; depending on the patient's size, alternative implant sites for such patients may include the buttocks or thigh. In addition, active infection and skin breakdown along the proposed course of the tunneled catheter are strong contraindications to placement (24). Based on atypical anatomy, device pockets have been reported in the lumbar region, thigh, and buttock as alternative sites.

\subsubsection{Panel Recommendations}

As there is limited evidence highlighting best practices for implanting a drug delivery system, clinicians are advised to follow a commonsense approach as outlined in Table 6 (116). It is also recommended that clinicians maintain a basic understanding of possible device malfunctions so that they can anticipate and address potential mechanical failures (Table 7) (195). Further, implantation consistency improves the clinician's ability to troubleshoot the device, and therefore barring necessary adjustments, it is advocated that surgeons be consistent in their implantation style.

\subsection{ECONOMIC FACTORS}

Optimal pain management for cancer patients should balance the effects of therapy with the overall cost of treatment. Since oral and intravenous opioid regimens are not associated with surgery-related adverse effects and allow for lower initial expenditure, systemic administration is generally preferred over more invasive intraspinal modalities, especially for patients with a limited life expectancy (21). However, IT therapy may be an appropriate and cost-effective treatment option for patients requiring short- or long-term therapy who may not respond to treatment with oral/ transdermal drug administration (21).

The economic impact of treatment for cancerrelated pain is directly correlated with a patient's life expectancy. Once considered to be strictly a terminal illness, many cancer patients are now living longer, largely due to earlier detection and medical advances (165). Data from the Surveillance, Epidemiology, and 
Table 6. Practical guidelines for minimizing mechanical failure and adverse effects

1. Understand all aspects of drug pump construction and programming.

2. Personally review initial pump programming.

3. Begin IT therapy with a conservative dose-even if the dose does not provide effective analgesia-and gradually titrate upward, as necessary.

4. Limit the use of highly concentrated solutions, which can cause an excessive delay in the development of adverse effects associated with slow infusion rates, when initiating therapy.

5. Avoid the use of CNS depressants immediately following device implantation.

6. Determine when the administered agents will first enter the IT space and convey this information to the patient and caregivers so that they can be vigilant for adverse effects during this high-risk time.

7. Avoid the use of conversion tables to calculate the initial starting dose; not only is this practice not supported by research, but doses formulated from standard conversion tables at equivalent analgesic amounts can be lethal.

IT $=$ intrathecal; $\mathrm{CNS}=$ central nervous system.

Table 7. Summary of potential pump failures

Catheter pump misconnection: A catheter pump misconnection typically occurs immediately following implantation, but may also be delayed in onset.

Loss of pump propellant: The loss of pump propellant can be revealed as an altered (excessive or reduced) rate of drug delivery and may result in a variety of symptoms, including overdose and acute withdrawal adverse effects.

Gear shaft wear and motor stall: These malfunctions lead to symptoms of drug underinfusion and may not be accompanied by an alarm.

Leakage of administered agent: Leakage may occur at the catheter-pump connection during the postoperative period or can be delayed in onset; these malfunctions can have several causes, including a needle piercing the catheter wall, infiltration of an additional local anesthetic utilized during incision site closure, trauma to the catheter caused by self-retaining or handheld "cat's paw" retractors, or catheter kinking proximate to the pump.

IT catheter displacement: Displacement of the catheter may result in CSF leakage, which can cause local hygroma.

IT catheter kinking: Kinking of the IT catheter can occur at any location, from the pump to the catheter receiving device; kinking makes it difficult or impossible to aspirate CSF and inject agents into the side of the pump.

IT catheter tip fibroma or fibrous sheath obstruction: An obstruction may be caused by increasing opioid doses or dose concentrations; obstruction can present as a decline in analgesic effect, new back pain, drug withdrawal symptoms, and/or possible neurologic adverse effects.

$$
\text { IT = intrathecal; CSF = cerebrospinal fluid. }
$$


End Results Cancer Statistics Review 1975-2005 indicate that 10-year survival rates for all invasive cancers have improved substantially from 1975 to 1995, increasing from $44.5 \%$ to $58.5 \%$, respectively (196). For those who respond to anticancer treatment, cancer can become a chronic condition that is often characterized by persistent physical symptoms necessitating long-term pain management (197). It is, therefore, essential to consider the prognosis of disease and the potential requirement for ongoing therapy when determining if a patient is best suited for systemic versus IT therapy.

Factors such as the cause of pain and duration of symptoms also greatly influence the economic implications of treatment, as escalating dosages and/or polypharmacy may be necessary to provide continued pain relief. Specifically, pain presentation is likely to vary in duration and severity, with up to $95 \%$ of cancer patients reporting episodes of breakthrough pain (198). Estimates have shown that cancer patients who experience breakthrough pain report substantially higher direct and indirect costs than those without breakthrough symptoms (198).

Results of a recent survey of health care practitioners who actively use implantable drug delivery systems found that $40.5 \%$ of those surveyed believed the cost of implantation to be the greatest economic barrier to initiating IT therapy (19). The cost of drug and drug refill fees is also influential, with only $25 \%$ of pain practitioners surveyed indicating that they were satisfied with the reimbursement received from private insurance companies (19). In fact, approximately $90 \%$ of respondents reported that reimbursement for filling, refilling, and programming medication pumps was insufficient to cover practice costs $(n=87)$ (19). Other economic considerations may also interfere with patient access to therapy, including the patient's ability to cover out-of-pocket expenses (19).

The cost of treatment is only one factor to consider during the patient selection process; the primary focus should remain relieving intractable pain. Nonetheless, the following model has been developed to compare the cost of systemic versus IT drug delivery-using current market prices to determine the economic impact of IT therapy-to assist clinicians in selecting the most appropriate therapy for their patients. Assuming all regimens provide equal efficacy, this example evaluates the cost of treatment with high- or low-end IT monotherapy (ziconotide vs morphine, respectively), compared with a brand name or generic oral regimen (Table 8) (199-202). In clinical practice, patients frequently require combination therapy to achieve and maintain effective analgesia; with regard to this example, the cost of most IT admixtures will fall between that of monotherapy with ziconotide and morphine.

Regardless of which IT regimen is used, initial device implantation costs, as well as monthly fees for pump refilling and/or reprogramming, are relatively high compared to systemic administration (Tables 9,10)

Table 8. Cost comparison of a high-end and a low-end it medication versus a brand name oral drug regimen and generic drug regimen (months) *

\begin{tabular}{|c|c|c|}
\hline Drug Regimen and Dose & Time (months/30 days) & Average Cost (\$) \\
\hline IT Prialt & 0 & 0 \\
\hline \multirow{5}{*}{ Average dose $4 \mu \mathrm{g} /$ day in $20-\mathrm{mL}$ Medtronic pump } & 1 & 781.20 \\
\hline & 2 & 1562.40 \\
\hline & 3 & 2343.60 \\
\hline & 4 & 3124.80 \\
\hline & 5 & 3906.00 \\
\hline \multirow{7}{*}{$\begin{array}{l}\text { Medicare J2278 unit measure billing per } 1 \mu \mathrm{g} \\
\text { ASP }+6 \%=\$ 6.51 / \mu \mathrm{g}\end{array}$} & 6 & 4687.20 \\
\hline & 7 & 5468.40 \\
\hline & 8 & 6249.60 \\
\hline & 9 & 7030.80 \\
\hline & 10 & 7812.00 \\
\hline & 11 & 8593.20 \\
\hline & 12 & 9374.40 \\
\hline
\end{tabular}


Table 8 (cont.). Cost comparison of a high-end and a low-end it medication versus a brand name oral drug regimen and generic drug regimen (months)*

\begin{tabular}{|c|c|c|}
\hline IT Morphine & 0 & 0 \\
\hline \multirow{5}{*}{ Average dose $6 \mathrm{mg} /$ day in Medtronic 20-mL pump } & 1 & 50.94 \\
\hline & 2 & 101.88 \\
\hline & 3 & 152.82 \\
\hline & 4 & 203.76 \\
\hline & 5 & 254.70 \\
\hline \multirow{2}{*}{ Medicare J2275 unit measure billing per $10 \mathrm{mg}$} & 6 & 305.64 \\
\hline & 7 & 356.58 \\
\hline \multirow[t]{5}{*}{$\mathrm{ASP}+6 \%=\$ 2.83 / 10 \mathrm{mg}$} & 8 & 407.52 \\
\hline & 9 & 458.46 \\
\hline & 10 & 509.40 \\
\hline & 11 & 560.34 \\
\hline & 12 & 611.28 \\
\hline Oral Brand Name Regimen & 0 & 0 \\
\hline \multirow{12}{*}{$\begin{array}{l}\text { OxyContin } 80 \mathrm{mg} 3 \text { times a day } \\
\text { Percocet } 10 / 325 \mathrm{mg} 8 \text { times a day } \\
\text { Lyrica } 150 \mathrm{mg} \text { twice a day } \\
\text { Cymbalta } 60 \mathrm{mg} \text { every day } \\
\text { Klonopin } 1 \mathrm{mg} \text { twice a day } \\
\text { Ambien CR } 12.5 \mathrm{mg} \text { at bedtime }\end{array}$} & 1 & 2856.00 \\
\hline & 2 & 5712.00 \\
\hline & 3 & 8568.00 \\
\hline & 4 & $11,424.00$ \\
\hline & 5 & $14,280.00$ \\
\hline & 6 & $17,136.00$ \\
\hline & 7 & $19,992.00$ \\
\hline & 8 & $22,848.00$ \\
\hline & 9 & $25,704.00$ \\
\hline & 10 & $28,560.00$ \\
\hline & 11 & $31,416.00$ \\
\hline & 12 & $34,272.00$ \\
\hline Oral Generic Regimen & 0 & 0 \\
\hline \multirow{12}{*}{$\begin{array}{l}\text { Methadone } 10 \mathrm{mg} 4 \text { times a day } \\
\text { Oxycodone } 15 \mathrm{mg} 4 \text { times a day } \\
\text { Gabapentin } 400 \mathrm{mg} 4 \text { times a day } \\
\text { Desipramine } 10 \mathrm{mg} 3 \text { times a day } \\
\text { Trazodone } 50 \mathrm{mg} \text { at bedtime }\end{array}$} & 1 & 318.00 \\
\hline & 2 & 636.00 \\
\hline & 3 & 954.00 \\
\hline & 4 & 1272.00 \\
\hline & 5 & 1590.00 \\
\hline & 6 & 1908.00 \\
\hline & 7 & 2226.00 \\
\hline & 8 & 2544.00 \\
\hline & 9 & 2862.00 \\
\hline & 10 & 3180.00 \\
\hline & 11 & 3498.00 \\
\hline & 12 & 3816.00 \\
\hline
\end{tabular}

IT = intrathecal; ASP = average sales price.. Data from Ref 199-202. 
(199-204). Nonetheless, IT delivery of either morphine or ziconotide is found to cost less than a brand name oral regimen even after accounting for these added expenses. As Fig. 2 demonstrates, the cost of an oral brand name regimen exceeds that of IT morphine or IT ziconotide (Prialt) after 7 months and 10 months of treatment, respectively $(199-202,205,206)$. In fact, a brand name oral therapy remains the most costly option after 10 years of treatment $(199,202,204-207)$. Compared to a brand name oral regimen or IT drug delivery, generic oral therapy remains the least expensive option regardless of the length of treatment (199-202). Patients, however, are unlikely to receive only oral generics to adequately manage their pain; clinicians may instead provide IT morphine as a comparable alternative to this lowest cost option.

When evaluating the costs of treatment, it is important to note that supplemental oral medications were not factored into this cost example. Particularly for cancer pain patients-who are likely to experience episodes of breakthrough pain and may have rapidly changing pain stimuli that require prompt adjustments-continued use of one or more oral medications in addition to IT drug delivery is often required to maintain effective analgesia (198). For instance, patients may require supplemental medications such as oral transmucosal fentanyl in addition to the primary IT regimen; at ap- proximately $\$ 250$ to $\$ 350$ for 2,400 to $3,200 \mu$ g per day, the added cost of treatment may increase substantially (208). Drug delivery via an adjunctive technology such as the Personal Therapy Manager (PTM) may provide a cost-effective solution for patients experiencing daily episodic changes in their pain; however, the extent to which this device produces a cost savings has yet to be determined $(209,210)$. It should also be recognized that this model is based on therapy with a programmable device, rather than a constant-flow drug delivery system. Largely due to the high level of patient satisfaction provided by allowing for dose adjustments that correspond with pain fluctuations, programmable pumps represent a considerable portion of the US market $(162,211)$. However, Medicare reimbursement varies for programmable and constant-flow devices, an additional factor that could influence treatment costs.

\subsection{Panel Recommendations}

Patient selection for IT delivery cannot be based on economic consequences alone; yet, consideration of the overall cost of therapy can assist in the development of a patient-centered treatment regimen. With consideration of life expectancy and the necessity for supplemental opioids to manage breakthrough pain, cancer patients may be appropriate candidates for IT drug delivery.

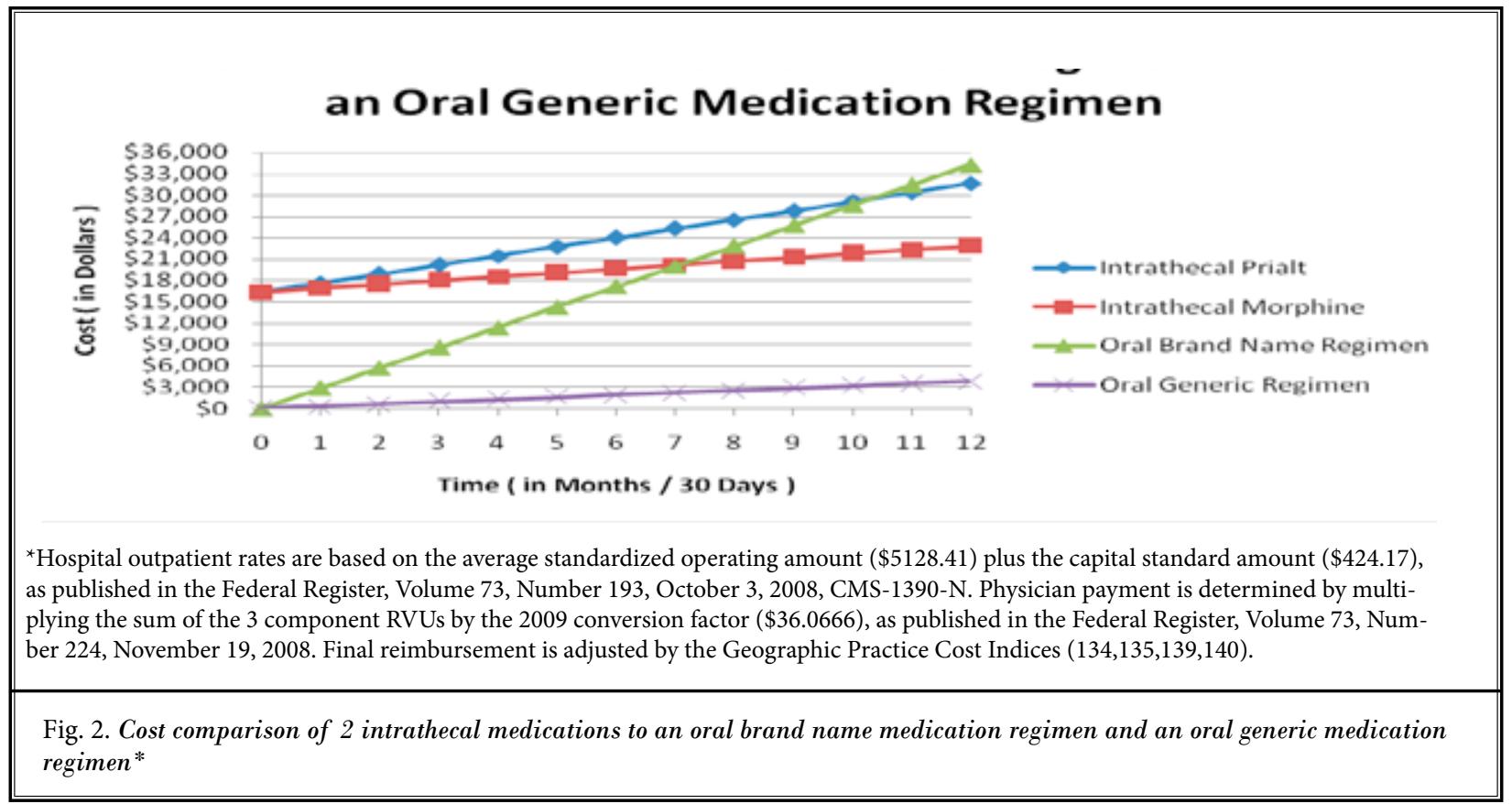




\section{Intrathecal Drug Delivery Systems Consensus-Based Guidelines}

Table 9. Initial pump expense and monthly refill costs (199-202)*

\begin{tabular}{|c|c|c|c|}
\hline \multicolumn{4}{|c|}{ Initial Pump Expense } \\
\hline Procedure & Physician Reimbursement (\$) & Clinic Reimbursement (\$) & Cost $(\$)$ \\
\hline Screening test & 89 & 474 & 563 \\
\hline Catheter insertion & 365 & 2777 & 3142 \\
\hline Pump placement & 384 & 12,282 & 12,666 \\
\hline & & TOTAL & 16,371 \\
\hline \multicolumn{4}{|c|}{ Monthly Refill Cost } \\
\hline Refill & 87 & 188 & 275 \\
\hline \multirow[t]{2}{*}{ Pump reprogramming } & 51 & 163 & 214 \\
\hline & & TOTAL & 489 \\
\hline
\end{tabular}

Data from Ref 199-202.

Table 10. Monthly costs, including initial pump cost and refills*

\begin{tabular}{|c|c|c|}
\hline Drug Regimen and Dose & Time (months/30 days) & Average Cost (\$) \\
\hline IT Prialt & 0 & $16,371.00$ \\
\hline \multirow{5}{*}{ Average dose $4 \mu \mathrm{g} / \mathrm{d}$ in 20 -mL Medtronic pump } & 1 & $17,641.20$ \\
\hline & 2 & $18,911.40$ \\
\hline & 3 & $20,181.60$ \\
\hline & 4 & $21,451.80$ \\
\hline & 5 & $22,722.00$ \\
\hline Medicare J2278 unit measure billing per $1 \mu \mathrm{g}$ & 6 & $23,992.20$ \\
\hline \multirow[t]{2}{*}{$\mathrm{ASP}+6 \%=\$ 6.51 / \mu \mathrm{g}$} & 7 & $25,262.40$ \\
\hline & 8 & $26,532.60$ \\
\hline \multirow{4}{*}{ Refills performed once a month } & 9 & $27,802.80$ \\
\hline & 10 & $29,073.00$ \\
\hline & 11 & $30,343.20$ \\
\hline & 12 & $31,613.40$ \\
\hline IT Morphine & 0 & $16,371.00$ \\
\hline \multirow{5}{*}{ Average dose $6 \mathrm{mg} / \mathrm{d}$ in Medtronic $20-\mathrm{mL}$ pump } & 1 & $16,910.94$ \\
\hline & 2 & $17,450.88$ \\
\hline & 3 & $17,990.82$ \\
\hline & 4 & $18,530.76$ \\
\hline & 5 & $19,070.70$ \\
\hline Medicare J2275 unit measure billing per $10 \mathrm{mg}$ & 6 & $19,610.64$ \\
\hline $\mathrm{ASP}+6 \%=\$ 2.83 / 10 \mathrm{mg}$ & 7 & $20,150.58$ \\
\hline \multirow{5}{*}{ Refills performed once a month } & 8 & $20,690.52$ \\
\hline & 9 & $21,230.46$ \\
\hline & 10 & $21,770.40$ \\
\hline & 11 & $22,310.34$ \\
\hline & 12 & $22,850.28$ \\
\hline
\end{tabular}

${ }^{*}$ Hospital outpatient rates are based on the average standardized operating amount (\$5128.41) plus the capital standard amount (\$424.17), as published in the Federal Register, Volume 73, Number 193, October 3, 2008, CMS-1390-N. Physician payment is determined by multiplying the sum of the 3 component RVUs by the 2009 conversion factor (\$36.0666), as published in the Federal Register, Volume 73, Number 224, November 19, 2008. Final reimbursement is adjusted by the Geographic Practice Cost Indices $(134,135,139,140)$. 


\subsection{Pre-Implant Trialing}

Serving as a final step in the selection process, patients typically undergo an IT therapy trial prior to permanent device implantation. Traditionally, IT trials have been used to determine patient response to therapy and establish a baseline measurement from which potential improvement can be assessed. Trials are often a mandatory requirement of insurance providers (e.g., Medicare), and as such, have become commonplace among physicians. Whereas trials may play an important role in long-term therapy, they have limited value for patients receiving palliative care where it is essential to be expeditious in evaluating treatment options. Additionally, a direct correlation between a patient's response during an IT trial and subsequent effects of therapy has yet to be established, thus limiting the predictive value of this screening technique, although Onofrio et al (131) suggested a standard trialing technique may have prognostic benefit in 53 consecutive cancer patients. Careful consideration is warranted when deciding how effective the process of trialing is in deciding which patients are appropriate candidates for IT device implantation.

\subsection{Screening Techniques}

IT trialing is widely used as a screening technique prior to device implantation, yet no standard method of implementation has been established and locations in which testing is performed vary greatly. Similarly, ideal trial duration has not been confirmed; although trials typically last several days, they can be conducted for a few hours or last for multiple weeks. By administering the selected treatment through a single injection, multiple injections, or continuous infusion, either in the intrathecal or epidural space, trialing can be initiated via epidural or IT delivery (Table 11). The decision to use one method over another is largely based on the physician's preference, availability of facilities, practice environment, and insurance/Medicare coverage provided $(98,212-214)$. Medicare requires placement of an intrathecal catheter for trialing, although this practice is rarely performed. The patient's overall condition is also an important factor, as patients who are gravely ill may require hospitalization to undergo IT trialing.

\subsubsection{Panel Recommendations:}

Ultimately it is up to the implanting clinician to weigh the benefits and limitations of each trialing method and decide which technique-if any-is best suited for the patient.

\subsection{Trial Goals}

IT screening has routinely been used to qualify or quantify patient response to therapy, the goal of which is to assist clinicians in identifying appropriate candidates for IT therapy. Commonly described as a $50 \%$ or greater improvement in pain score as measured by an accepted tool (e.g., visual analog scale), a positive trial has traditionally been thought to be indicative of future success with IT drug delivery (135). Trialing has also been used as a means to monitor for the development of unacceptable adverse effects prior to committing to permanent device implantation (209). Many use the trial as a rapport builder to substantiate the safety and benefit of intrathecal drug delivery, not as a prognostic measure of therapy success or failure.

Limited by the number of approved IT opioid agents, the perception of trial goals has largely been based on subjective end points related to the pharmacologic effects of the selected therapy. However, the advent of novel nonopioid IT agents has broadened the armamentarium of available therapies, thereby diminishing the predictive value for determining longterm effects of treatment (215). The uncertainty of trial goals is furthered exemplified by the lack of consistency between comparative pain relief data associated with opioid trial agents (primarily morphine) and other drug classes or admixtures that are not suitable for use in trial settings (216).

The ambiguity of IT trial goals is also revealed by the limited data demonstrating the predictive value of pre- and post-implantation responses; in fact, the only evidence that supports the prognostic significance of trials comes from retrospective studies $(130,216)$. Furthermore, a direct correlation between a positive trial and subsequent therapeutic success has not been confirmed. For example, a prospective study of 18 patients reported that all participants experienced at least a $50 \%$ reduction in pain during a trial with IT morphine or sufentanil; however, during a mean follow-up time of 2.4 years post-implantation, $39 \%$ of these patients reported no reduction in pain (217). Another study demonstrated that despite achieving good pain relief following a single-dose trial, long-term analgesic effect from IT therapy may be insufficient with a permanent drug delivery device (218). Finally, physical restrictions in the epidural space such as that found in patients with large invasive tumors may skew trial results and discount the potential benefit that could be derived from permanent pump placement. 
Table 11. Screening trial methods: advantages and disadvantages

\begin{tabular}{|c|c|c|c|}
\hline & Trialing Method & Advantages & Disadvantages \\
\hline \multirow{2}{*}{$\begin{array}{c}\text { Single } \\
\text { injection }^{*}\end{array}$} & Epidural & $\begin{array}{l}\text { Low cost } \\
\text { Minimal time commitment } \\
\text { No PDPH }\end{array}$ & $\begin{array}{l}\text { High placebo response } \\
\text { Systemic drug effects } \\
\text { Does not mimic chronic drug infusion }\end{array}$ \\
\hline & Intrathecal & $\begin{array}{l}\text { Low cost } \\
\text { Minimal time commitment }\end{array}$ & $\begin{array}{l}\text { High placebo response } \\
\text { PDPH may interfere with trial } \\
\text { Does not mimic chronic drug infusion }\end{array}$ \\
\hline \multirow{2}{*}{$\begin{array}{l}\text { Multiple } \\
\text { injections }\end{array}$} & Epidural & $\begin{array}{l}\text { No PDPH } \\
\text { Can use placebo control }\end{array}$ & $\begin{array}{l}\text { Systemic drug effects } \\
\text { Dose not mimic chronic drug infusion }\end{array}$ \\
\hline & Intrathecal & Can use placebo control & $\begin{array}{l}\text { PDPH may interfere with trial } \\
\text { Does not mimic chronic drug infusion }\end{array}$ \\
\hline \multirow[b]{2}{*}{$\begin{array}{l}\text { Continuous } \\
\text { infusion }\end{array}$} & Epidural & $\begin{array}{l}\text { No PDPH } \\
\text { Less placebo response }\end{array}$ & $\begin{array}{l}\text { High cost } \\
\text { Systemic drug effects } \\
\text { Labor intensive } \\
\text { Does not mimic chronic drug infusion } \\
\text { Risk of infection } \\
\text { Many insurances do not cover home infusion }\end{array}$ \\
\hline & Intrathecal & $\begin{array}{l}\text { Mimics chronic drug infusion } \\
\text { Possibly less placebo response }\end{array}$ & $\begin{array}{l}\text { High cost } \\
\text { Labor intensive } \\
\text { PDPH may interfere with trial } \\
\text { Risk of infection } \\
\text { Many insurances to not cover home infusion }\end{array}$ \\
\hline No trial & - & $\begin{array}{l}\text { No cost } \\
\text { No time commitment } \\
\text { No possibility for placebo response } \\
\text { No hospitalization required }\end{array}$ & $\begin{array}{l}\text { Many insurers will not cover device implantation } \\
\text { without first conducting a preoperative trial }\end{array}$ \\
\hline
\end{tabular}

${ }^{*}$ Medicare requires a preliminary IT trial utilizing a temporary IT/epidural catheter; reimbursement may not be available for trialing conducted via single or multiple injections.

$\mathrm{PDPH}=$ postdural puncture headache.

\subsubsection{Panel Recommendations:}

Acknowledging these inconsistencies between trial outcomes and actual therapeutic response is important when determining the usefulness of IT screening, particularly for cancer patients with limited life expectan$c y$, where the urgency to find an effective treatment is of upmost importance.

\subsection{Implications for Cancer Patients}

Available trialing methods are often time-consuming and fail to simulate the precise mechanisms of treatment, limiting the ability of screening techniques to anticipate the effects of long-term therapy. Nonetheless, published trial guides, expert consensus, and review articles have consistently recommended an IT therapy trial as an essential step in the patient selection process $(4,34,218)$. In fact, current Medicare guidelines require opioid testing via a temporary IT/epidural catheter to "substantiate adequately acceptable pain relief and degree of side effects (including effects on the activities of daily living) and patient acceptance" for permanent device implantation to be covered (219).

The 2007 Polyanalgesic Consensus Conference panelists also urge the continuation of trialing-allowing for the implanting physician to determine the most appropriate screening method-until data deem the trials unnecessary (6). During the 2003 Polyanalgesic Consensus Conference, panelists discussed "the potential for varied 
effects from differences in dosage, infusion rate, and concentration," commenting that "the time-consuming strategy of conducting trials systematically by varying only 1 parameter at a time might be best for judging drug effects, but is impractical in most clinical settings" (220). This method may ultimately improve patient response to therapy, however, it is not reasonable for patients at the end of life due to the time required to adequately rotate through each potential IT agent.

\subsubsection{Panel Recommendations}

Although the panel supports the practice of trialing when deemed necessary by the implanting physician, it recommends reconsideration of mandatory IT trials, particularly for patients near the end of life. Substantial evidence supports the use of IT therapy in providing significant pain relief for patients with cancer-related pain $(108,109)$. As such, clinicians are urged to prevent delays in administering effective analgesia to patients with progressive cancer by foregoing an IT trial, provided they are otherwise reasonable candidates for an implantable drug delivery device. For many cancer patients with uncontrolled pain, few options exist aside from IT therapy to provide sufficient pain relief. The compassionate and appropriate approach in treating these individuals requires clinicians to act expeditiously in deciding to proceed with IT therapy.

\subsection{Prognosis of Disease-Device CHOICE}

In the context of other factors-such as patient support systems, the patient's proximity to the health care facility, physician experience, local-regional availability of specialized home care, and cost-effectiveness-clinicians typically consider a patient's disease prognosis as the basis for selecting an implantable IT drug delivery system $(126,203,221)$. Neuraxial analgesia options include percutaneous short-term IT catheter, a long-term tunneled IT catheter, and a fully implantable infusion pump and catheter system.

Conventional wisdom dictates percutaneous external systems for those with less than a 3-month life expectancy $(8,203)$. Implanted at the patient's home or in a palliative unit-or even the hospice setting-the simple percutaneous catheter placement is completed in approximately 20 minutes, causes minimal patient discomfort, and is relatively inexpensive (8). In contrast to a short-term IT catheter, the one-hour procedure to implant a long-term tunneled catheter or fully internalized system requires fluoroscopic guidance and necessitates sterile conditions to minimize the risk for surgical adverse events (8). Although externalized systems are initially less expensive than implantable devices, they are associated with higher long-term costs as a result of the requirement for ongoing monitoring (8). A comparative 1991 study by Bedder and colleagues (203) concluded that clinicians should consider the use of fully implantable drug delivery systems only in patients whose life expectancy exceeds 3 months, as the cost benefit of this pain management strategy accrues over the long term. Since doctors are very poor at predicting life expectancy, these considerations have little validity in most patients.

Local-regional preferences may also guide the clinician's decision-making process. In many rural areas, the difficulties of maintaining an external infusion system and home delivery of medications may mitigate against percutaneous systems in some settings, regardless of life expectancy. Further, the availability of $40 \mathrm{~mL}$ reservoir pumps with highly concentrated medicine can help decrease the need for refills.

\subsection{Panel Recommendations}

The panel recommends that the use of IT analgesia be applied in advanced cancer patients with careful consideration of the following factors to guide the optimal delivery device/mechanism: 1) patient support systems, 2) the patient's proximity to the health care facility, 3) local-regional availability of specialized home care, 4) physician experience, and 5) life expectancy/ cost-effectiveness considerations. Although a patient with a very short life expectancy may not be ideal for an implanted pump, the panel views a recommendation solely based on life expectancy as oversimplified and not useful.

\subsection{Limitations}

The limitations on these guidelines include that these are expert panel guidelines. The literature describes appropriate preparation of guidelines based on evidence derived from randomized trials and systematic reviews (222-240). These issues are important, specifically in the era of exploding health care costs and utilization of multiple interventional techniques $(2,55$ $58,222-240)$. However, there is also value for consensusbased guidelines due to non-availability of evidence from either systematic reviews of randomized trials or randomized trials alone. In addition, the evidence is not available on many aspects of intrathecal infusion systems even with observational studies and case reports. Thus, the present approach with expert consensus guidelines is acceptable. 


\subsection{Conclusion}

As demonstrated by numerous prospective and/ or randomized controlled trials, IT therapy can significantly help cancer patients with severe pain $(3,4,11)$; however, there has been relatively limited application of this treatment modality due to the difficulties outlined in this article. Yet, with careful consideration of the patient's medical comorbidities and prior therapies, communication with the oncologist, proper psychological evaluation, and appropriate trialing technique, clinicians can effectively optimize the use of IT therapy for cancer pain. The panel advocates a much wider application of IT therapy to provide meaningful analgesia for patients with cancer pain including those at the end of life.

\subsection{Clinical Practice Pearls}

Educate our oncology colleagues at any given opportunity about this often overlooked, evidence-based, effective treatment for refractory cancer pain.

Work closely with the patient's oncologist, to ensure seamless integration of implantation of a drug delivery system while avoiding significant interruption of oncologic treatment protocols. Collaborate to work between nadirs in neutrophil and platelet counts to minimize the risk of surgical complications.

Although advanced cancer patients have many comorbidities including active infection, these issues need not rule out IT therapy provided they are appropriately managed pre- and post-implantation as dictated by disease-specific guidelines.

Before implanting a pump, the patient's ability to comply with medication refill schedules-whether due to geographic limitations and limited ability to travel, or limited financial resources-must be considered. End-of-life patients may merit consideration of a $40 \mathrm{~mL}$ pump and a highly concentrated refill prior to hospice enrollment to diminish the likelihood of needing a refill for many months.

The panel members are referred many end-of-life patients who are caught in an irreversible downward spiral of symptoms and illness trajectory. The panel urges that referral for consideration of IT device implantation be made before the patient is in the downward illness trajectory spiral to avoid needless suffering.

\section{Disclosures}

Dr. Timothy Deer had full access to the data in this study, and, takes responsibility for the integrity of the data and the accuracy of the data analysis. Dr. Deer, Dr. Smith, Dr. Cousins, Dr. Burton, Dr. Pope, Dr. Doleys,
Dr. Levy, Dr. Staats, Dr. Wallace, Dr. Webster, and Dr. Rauck managed the literature search, wrote various sections, and edited the final manuscript. All authors provided content for and revision of intellectual content and final approval of the manuscript.

Conflict of Interest: The authors of this manuscript received no remuneration. Further, the authors have not received any reimbursement or honorarium in any other manner. The following authors have the following conflicts to report:

Dr. Timothy Deer is a consultant for Inset, Medtronic, Codman and Azur.

Dr. Allen Burton is a consultant for Medtronic and a speaker for Azur, Pricara, Neurogesx, Pfizer, Cephalon and Cadence

Dr. Jason Pope has nothing to disclose.

Dr. Daniel Doleys is a speaker for Medtronic

Dr. Robert Levy is a consultant for Medtronic and Codman \& Shurtleff.

Dr. Peter Staats has received research grants and honoraria from Medtronic.

Dr. Mark Wallace has received research support from Medtronic and is a speaker for Azur

Dr. Lynn Webster has received research support from Medtronic.

Dr. Richard Rauck is a consultant for Inset, Medtronic, Infusion Systems and Elan.

Dr. Michael Cousins is a consultant for Medtronic

All authors are members of the American Society of Interventional Pain Physicians (ASIPP) except for Dr. Levy, Dr. Rauck and Dr. Cousins. All authors are practicining physicians.

Funding/Support: The authors wish to disclose and thank the sponsor of the manuscript. The direct manuscript development costs were funded by a grant from Inset Technologies. Inset had no influence on the development and resulting conclusions of this manuscript.

Role of Sponsor: The financial sponsor of this work had no role in the design, management, analysis or interpretation of the data. The sponsor also did not have a role in the preparation or review of the manuscript or the decision to submit.

\section{Acknowledgments}

The authors also wish to thank Jessica Steuerman, Senior Educational Program Director, North American Center for Continuing Medical Education (NACCME), who assisted in the preparation of the manuscript. We would also like to thank the editorial board of Pain Physician for review and criticism in improving the manuscript. 


\section{References}

1. van den Beuken-van Everdingen $\mathrm{MH}$, de Rijke JM, Kessels AG, Schouten HC, van Kleef M, Patijn J. Prevalence of pain in patients with cancer: A systematic review of the past 40 years. Ann Oncol 2007; 18:14371449.

2. Manchikanti L. Singh V, Datta S, Cohen SP, Hirsch JA. Comprehensive review of epidemiology, scope, and impact of spinal pain. Pain Physician 2009; 12:E35-E70.

3. Staats PS, Yearwood T, Charapata SG, Presley RW, Wallace MS, Byas-Smith M, Fisher R, Bryce DA, Mangieri EA, Luther RR, Mayo M, McGuire D, Ellis D.. Intrathecal ziconotide in the treatment of refractory pain in patients with cancer or AIDS. JAMA 2004; 291:63-70.

4. Smith TJ, Staats, PS, Deer T, Stearns LJ, Rauck RL, Boortz-Marx RL, Buchser E, Català E, Bryce DA, Coyne PJ, Pool GE; Implantable Drug Delivery Systems Study Group.. Randomized clinical trial of an implantable drug delivery system compared with comprehensive medical management for refractory cancer pain: impact on pain, drug-related toxicity, and survival. J Clin Oncol 2002; 20:4040-4049.

5. Smith TJ, Coyne PJ, Staats PS, Deer T, Stearns LJ, Rauck RL, Boortz-Marx RL, Buchser E, Català E, Bryce DA, Cousins M, Pool GE. An implantable drug delivery system (IDDS) for refractory cancer pain provides sustained pain control, less drug-related toxicity, and possibly better survival compared with comprehensive medical management (CMM). Ann Oncol 2005; 16:825833.

6. Deer T, Krames ES, Hassenbusch SJ, Burton, A., Caraway, D., Dupen, S., Eisenach, J., Erdek, M., Grigsby, E., Kim, P., Levy, R., McDowell, G., Mekhail, N., Panchal, S., Prager, J., Rauck, R., Saulino, M., Sitzman, T., Staats, P., Stanton-Hicks, M., Stearns, L., Willis, K. D., Witt, W., Follett, K., Huntoon, M., Liem, L., Rathmell, J., Wallace, M., Buchser, E., Cousins, M. and Ver Donck, A. Polyanalgesic Consensus Conference 2007: recommendations for the management of pain by intrathecal (intraspinal) drug delivery: Report of an interdisciplinary expert panel. Neuromodulation 2007; 10:300-328.

7. Burton AW, Rajagopal A, Shah HN, Mendoza T, Cleeland C, Hassenbusch SJ 3rd, Arens JF. Epidural and intrathecal analgesia is effective in treating refractory cancer pain. Pain Medicine 2004; 5:239-247.

8. Stearns L, Boortz-Marx R, Du Pen S, Friehs G, Gordon M, Halyard M, Herbst L, Kiser J. Intrathecal drug delivery for the management of cancer pain: A multidisciplinary consensus of best clinical practices. J Support Oncol 2005; 3:399-408.

9. Foley KM. Acute and chronic cancer pain syndromes. In Doyle D, Hanks G, Cherny $\mathrm{N}$, Calman K (eds). Oxford Textbook of Palliative Medicine 3 rd ed. Oxford University Press, Oxford, United Kingdom, 2004, pp 298-316.

10. Krakovsky AA. Complications associated with intrathecal pump drug delivery: A retrospective evaluation. Am J Pain Manag 2007; 17:4-10.

11. Rauck RL, Cherry D, Boyer MF, Kosek P, Dunn J, Alo K. Long-term intrathecal opioid therapy with a patient-activated, implanted delivery system for the treatment of cancer pain. J Pain 2003; 4:441-447.

12. Becker R, Jakob D, Uhle E, Riegel T, Bertalanffy $\mathrm{H}$. The significance of intrathecal opioid therapy for the treatment of neuropathic cancer pain conditions. Stereotact Funct Neurosurg 2000; 75:16-26.

13. Ghafoor VL, Epshteyn M, Carlson GH, Terhaar DM, Chany O, Phelps PK. Intrathecal drug therapy for long-term pain management. Am J Health Syst Pharm 2007; 64:2447-2461.

14. Belverud A, Mogilner A, Schulder M. Intrathecal pumps. Neurotherapeutics 2008; 5:114-122.

15. Walker SM, Goudas LC, Cousins MJ, Carr DB. Combination spinal analgesic chemotherapy: A systematic review. Anesth Analg 2002; 95:674-715.

16. Siddall PJ, Molloy AR, Walker S, Rutkowski SB, Cousins MJ. The efficacy of intrathecal morphine and clonidine in the treatment of pain after spinal cord injury. Anesth Analg 2000; 91:1493-1498.

17. Rainov NG, Heidecke V, Burker W. Longterm intrathecal infusion of drug combinations for chronic back and leg pain. J Pain Symptom Manage 2001; 22:862-871.

18. Wallace MS, Kosek PS, Staats P, Fisher R, Schultz DM, Leong M. Phase II, open-label, multicenter study of combined intrathecal morphine and ziconotide: Addition of ziconotide in patients receiving intrathecal morphine for severe chronic pain. Pain Med 2008; 9:271-281.

19. Deer TR, Krames E, Levy RM, Hassenbusch SJ, Prager JP. Practice choices and challenges in the current intrathecal therapy environment: An online survey. Pain Med 2009; 10:304-309.

20. Smith HS, Deer TR. Safety and efficacy of intrathecal ziconotide in the management of severe chronic pain. Ther Clin Risk Manag 2009; 5:521-534. Epub 2009 Jul 12.
21. Deer T, Winkelmuller W, Erdine S, Bedder M, Burchiel K. Intrathecal therapy for cancer and nonmalignant pain: Patient selection and patient management. Neuromodulation 1999; 2:55-66.

22. Deer T, Chapple I, Classen A, Javery K, Stoker V, Tonder L, Burchiel K. Intrathecal drug delivery for treatment of chronic low back pain: Report from the National Outcomes Registry for Low Back Pain. Pain Med 2004; 5:6-13.

23. Appelgren L, Nordbong C, Sjoberg M, Karlsson PA, Nitescu P, Curelasu I. Spinal epidural metastasis: Implications for spinal analgesia to treat "refractory" cancer pain. J Pain Symptom Manage 1997; 13:2542.

24. Follet KA, Boortz-Marx RL, Drake JM, DuPen S, Schneider SJ, Turner MS, Coffey RJ. Prevention and management of intrathecal drug delivery and spinal cord stimulation system infections. Anesthesiology 2004; 100:1582-1594.

25. Rosen S, Deer T, Rauck R, et al. Multi-center evaluation of drug delivery accuracy with the Prometra ${ }^{\circledR}$ intrathecal infusion pump. Pain Med 2009; 10:124.

26 Berg A, Barsa J, Deer T, Dwarakanath G, Padda G, Rauck R, Rosen S. Efficacy of morphine sulfate infusion via the Prometra ${ }^{\circledR}$ intrathecal infusion pump. A prospective multi-center evaluation. Poster presented at: 5 th World Congress Institute of Pain; March 15, 2009; New York, NY.

27. Ilias W, Polain B, Buchser E, Demartini L. Patient-controlled analgesia in chronic pain patients: Experience with a new device designed to be used with implanted programmable pumps. Pain Pract 2008; 8:164-170.

28. Wallace MS, Rauck R, Fisher R, Charapata SG, Ellis D, Dissanayake S. Intrathecal ziconotide for severe chronic pain: Safety and tolerability results of an open-label, long-term trial. Anesth Analg 2008; 106:628-637.

29. Rauck RL, Wallace MS, Leong MS, Minehart M, Webster LR, Charapata SG, Abraham JE, Buffington DE, Ellis D, Kartzinel R; Ziconotide 301 Study Group. A randomized, double-blind, placebo-controlled study of intrathecal ziconotide in adults with severe chronic pain. J Pain Symptom Manage 2006; 31:393-406.

30. Wallace MS, Charapata SG, Fisher R, Byas-Smith M, Staats P, Mayo M, McGuire D, Ellis D. Intrathecal ziconotide in the treatment of chronic nonmalignant pain: A randomized, double-blind, placebo-controlled clinical trial. Neuromodula- 
tion 2006; 9:75-86.

31. Webster LR, Fisher R, Charapata S, Wallace MS. Long-term intrathecal ziconotide for chronic pain: An open-label study. J Pain Symptom Manage 2009; 37:363-372.

32. Canavero S, Bonicalzi V, Clemente M. No neurotoxicity from long-term ( $>5$ years) intrathecal infusion of midazolam in humans. J Pain Symptom Manage 2006; 32:13 .

33. Yaksh TL, Allen JW. The use of intrathecal midazolam in humans: A case study of process. Anesth Analg 2004; 98:1536-1545

34. Knight $\mathrm{KH}$, Brand FM, Mchaourab AS, Veneziano G. Implantable intrathecal pumps for chronic pain: Highlights and updates. Croat Med J 2007; 48:22-34.

35. Sosnowski M, Yaksh TL. Role of spinal adenosine receptors in modulating the hyperesthesia produced by spinal glycine receptor antagonism. Anesth Analg 1989; 69:587-592.

36. Lee YW, Yaksh TL. Pharmacology of the spinal adenosine receptor which mediates the antiallodynic action of intrathecal adenosine agonists. J Pharmacol Exp Ther 1996; 277:1642-1648.

37. Karlsten R, Gordh T Jr. An Al-selective adenosine agonist abolishes allodynia elicited by vibration and touch after intrathecal injection. Anesth Analg 1995; 80:844-847.

38. Rane K, Segerdahl M, Goiny M, Sollevi A. Intrathecal adenosine administration: A phase 1 clinical safety study in healthy volunteers, with additional evaluation of its influence on sensory thresholds and experimental pain. Anesthesiology 1998; 89:1108-1115.

39. Belfrage $M$, Segerdahl M, Arnér S, Sollevi A. The safety and efficacy of intrathecal adenosine in patients with chronic neuropathic pain. Anesth Analg 1999; 89:136-142.

40. Coderre TJ, Kumar N, Lefebvre CD, Yu JSC. Evidence that gabapentin reduces neuropathic pain by inhibiting the spinal release of glutamate. J Neurochem 2005; 94:1131-1139.

41. Field MJ, Hughes J, Singh L. Further evidence for the role of the alpha(2)delta subunit of voltage dependent calcium channels in models of neuropathic pain. $\mathrm{Br}$ J Pharmacol 2000; 131:282-286.

42. Cheng JK, Chen CC, Yang JR, Chiou LC. The antiallodynic action target of intrathecal gabapentin: Ca2+ channels, KATP channels or N-methyl-d-aspartic acid receptors? Anesth Analg 2006; 102:182-187.

43. Hayashida K, Obata H, Nakajima K, Eisenach JC. Gabapentin acts within the locus coeruleus to alleviate neuropathic pain. Anesthesiology 2008; 109:1077-1084.

44. Van Elstraete AC, Sitbon P, Mazoit JX, Benhamou D. Gabapentin prevents delayed and long-lasting hyperalgesia induced by fentanyl in rats. Anesthesiology 2008; 108:484-494.

45. Lin JA, Lee MS, Wu CT, Yeh CC, Lin SL, Wen $\mathrm{ZH}$, Wong CS. Attenuation of morphine tolerance by intrathecal gabapentin is associated with suppression of morphine-evoked excitatory amino acid release in the rat spinal cord. Brain Res 2005; 1054:167-173.

46. Granados-Soto V, Arguelles CF. Synergic antinociceptive interaction between tramadol and gabapentin after local, spinal, and systemic administration. Pharmacology 2005; 74:200-208.

47. Kroin JS, Ling ZD, Buvanendran A, Tuman $\mathrm{KJ}$. Upregulation of spinal cyclooxygenase-2 in rats after surgical incision. Anesthesiology 2004; 100:364-369.

48. Yaksh TL, Horais KA, Tozier N, Rathbun M, Richter P, Rossi S, Grafe M, Tong C, Meschter C, Cline JM, Eisenach J. Intrathecal ketorolac in dogs and rats. Toxico Sci 2004; 80:322-334.

49. Szabo T, Olah Z, ladarola MJ, Blumberg PM. Epidural resiniferatoxin induced prolonged regional analgesia to pain. Brain Res 1999; 840:92-98.

50. Brown DC, ladarola MJ, Perkowski SZ, Erin H, Shofer F, Laszlo KJ, Olah Z, Mannes AJ. Physiologic and antinociceptive effects of intrathecal resiniferatoxin in a canine bone cancer model. Anesthesiology 2005; 103:1052-1059.

51. Allen JW, Mantyh PW, Horais K, Tozier N Rogers SD, Ghilardi JR, Cizkova D, Grafe MR, Richter P, Lappi DA, Yaksh TL. Safety evaluation of intrathecal substance $P$ Saporin, a targeted neurotoxin, in dogs. Toxicol Sci 2006; 91:286-298.

52. Wiley RG. Substance P receptor-expressing dorsal horn neurons: Lessons from the targeted cytotoxin, substance P-saporin. Pain 2008; 136:7-10.

53. Resiniferatoxin to treat severe pain associated with advanced cancer. ClinicalTrials.gov. clinicaltrials.gov/ct2/show/ NCToo804154. Accessed September 22, 2009.

54. Deer TR, Smith HS, Cousins M, Dolevs DM, Levy RM, Rathmell JP. Consensus guidelines for the selection and implantation of patients with noncancerk pain for intrathecal drug delivery. Pain Physician 2010; 13:E175-E213.

55. Manchikanti L, Boswell MV, Singh V, Benyamin RM, Fellows B, Abdi S, Buenaventura RM, Conn A, Datta S, Derby R, Falco
FJE, Erhart S, Diwan S, Hayek SM, Helm S, Parr AT, Schultz DM, Smith HS, Wolfer LR, Hirsch JA. Comprehensive evidencebased guidelines for interventional techniques in the management of chronic spinal pain. Pain Physician 2009; 12:699-802.

56. Manchikanti L, Boswell MV, Singh V, Derby R, Fellows B, Falco FJE, Datta S, Smith HS, Hirsch JA. Comprehensive review of neurophysiologic basis and diagnostic interventions in managing chronic spinal pain. Pain Physician 2009; 12:E71-E120.

57. Manchikanti L, Boswell MV, Datta S, Fellows B, Abdi S, Singh V, Benyamin RM, Falco FJE, Helm S, Hayek S, Smith HS. Comprehensive review of therapeutic interventions in managing chronic spinal pain. Pain Physician 2009; 12:E123-E198.

58. Manchikanti L, Helm S, Singh V, Benyamin RM, Datta S, Hayek S, Fellows B, Boswell MV. An algorithmic approach for clinical management of chronic spinal pain. Pain Physician 2009; 12:E225-E264.

59. Manchikanti L, Singh V, Falco FJE, Cash KA, Pampati V, Fellows B. Comparative effectiveness of a one-year follow-up of thoracic medial branch blocks in management of chronic thoracic pain: A randomized, double-blind active controlled trial. Pain Physician 2010; 13:535-548.

6o. Manchikanti L, Singh V, Falco FJ, Cash KA, Fellows B. Cervical medial branch blocks for chronic cervical facet joint pain: A randomized double-blind, controlled trial with one-year follow-up. Spine (Phila Pa 1976) 2008; 33:1813-1820.

61_. Manchikanti L, Singh V, Falco FJE, Cash KA, Fellows B. Comparative outcomes of a 2-year follow-up of cervical medial branch blocks in management of chronic neck pain: A randomized, double-blind controlled trial. Pain Physician 2010; 13:437450.

62. Manchikanti L, Singh V, Falco FJ, Cash KA, Pampati V. Lumbar facet joint nerve blocks in managing chronic facet joint pain: One-year follow-up of a randomized, double-blind controlled trial: Clinical Trial NCToo355914. Pain Physician 2008; 11:121-132.

63. Manchikanti L, Singh V, Falco FJE, Cash KA, Pampati V. Evaluation of lumbar facet joint nerve blocks in managing chronic low back pain: A randomized, doubleblind, controlled trial with a 2-year followup. Int J Med Sci 2010; 7:124-135.

64. Manchikanti L, Cash RA, McManus CD, Pampati V, Fellows B. Fluoroscopic caudal epidural injections with or without steroids in managing pain of lumbar spinal stenosis: One year results of randomized, 
double-blind, active-controlled trial. ] Spinal Disord 2011; accepted for publication.

65. Manchikanti L, Singh V, Cash KA, Pampati V, Damron KS, Boswell MV. A randomized, controlled, double-blind trial of fluoroscopic caudal epidural injections in the treatment of lumbar disc herniation and radiculitis. Spine (Phila Pa 1976) 2011; accepted for publication.

66. Manchikanti L, Cash KA, Pampati V, Wargo BW, Malla Y. Cervical epidural injections in chronic discogenic neck pain without disc herniation or radiculitis: Preliminary results of a randomized, doubleblind, controlled trial. Pain Physician 2010; 13:E265-E278.

67. Manchikanti L, Cash KA, Pampati V, Wargo BW, Malla Y. The effectiveness of fluoroscopic cervical interlaminar epidural injections in managing chronic cervical disc herniation and radiculitis: Preliminary results of a randomized, double-blind, controlled trial. Pain Physician 2010; 13:223236.

68. Manchikanti L, Singh V, Falco FJE, Cash KA, Pampati V. Evaluation of the effectiveness of lumbar interlaminar epidural injections in managing chronic pain of lumbar disc herniation or radiculitis: A randomized, double-blind, controlled trial. Pain Physician 2010; 13:343-355.

69. Manchikanti L, Cash KA, McManus CD, Pampati $\mathrm{V}$, Benyamin RM. A preliminary report of a randomized double-blind, active controlled trial of fluoroscopic thoracic interlaminar epidural injections in managing chronic thoracic pain. Pain Physician 2010; 13:E357-E369.

70. Manchikanti L, Cash KA, McManus CD, Pampati V, Smith HS. One year results of a randomized, double-blind, active controlled trial of fluoroscopic caudal epidural injections with or without steroids in managing chronic discogenic low back pain without disc herniation or radiculitis. Pain Physician 2011; 14:25-36.

71. Manchikanti L, Cash KA, McManus CD, Pampati V, Benyamin RM. Preliminary results of a randomized, double-blind, controlled trial of fluoroscopic lumbar interlaminar epidural injections in managing chronic lumbar discogenic pain without disc herniation or radiculitis. Pain Physician 2010; 13:E279-E292

72. Manchikanti L, Singh V, Cash KA, Pampati V, Datta S. Management of pain of post lumbar surgery syndrome: One-year results of a randomized, double doubleblind, active controlled trial of fluoroscopic caudal epidural injections. Pain Physician 2010; 13:509-521.
73. Manchikanti L, Cash KA, McManus CD, Pampati V, Singh V, Benyamin RM. The preliminary results of a comparative effectiveness evaluation of adhesiolysis and caudal epidural injections in managing chronic low back pain secondary to spinal stenosis: A randomized, equivalence controlled trial. Pain Physician 2009; 12:E341E354.

74. Manchikanti L, Singh V, Cash KA, Pampati $V$, Datta S. A comparative effectiveness evaluation of percutaneous adhesiolysis and epidural steroid injections in managing lumbar post surgery syndrome: A randomized, equivalence controlled trial. Pain Physician 2009; 12:E355-E368.

75. Patel VB, Manchikanti L, Singh V, Schultz DM, Hayek SM, Smith HS. Systematic review of intrathecal infusion systems for long-term management of chronic noncancer pain. Pain Physician 2009; 12:345360.

76. Falco FJE, Erhart S, Wargo BW, Bryce DA, Atluri S, Datta S, Hayek SM. Systematic review of diagnostic utility and therapeutic effectiveness of cervical facet joint interventions. Pain Physician 2009; 12:323344 .

77. Datta S, Lee M, Falco FJE, Bryce DA, Hayek SM. Systematic assessment of diagnostic accuracy and therapeutic utility of lumbar facet joint interventions. Pain Physician 2009; 12:437-460.

78. Conn A, Buenaventura R, Datta S, Abdi S, Diwan S. Systematic review of caudal epidural injections in the management of chronic low back pain. Pain Physician 2009; 12:109-135

79. Parr AT, Diwan S, Abdi S. Lumbar interlaminar epidural injections in managing chronic low back and lower extremity pain: A systematic review. Pain Physician 2009; 12:163-188.

8o. Benyamin RM, Singh V, Parr AT, Conn A, Diwan S, Abdi S. Systematic review of the effectiveness of cervical epidurals in the management of chronic neck pain. Pain Physician 2009; 12:137-157.

81. Buenaventura RM, Datta S, Abdi S, Smith HS. Systematic review of therapeutic lumbar transforaminal epidural steroid injections. Pain Physician 2009; 12:233-251.

82. Rupert MP, Lee M, Manchikanti L, Datta $S$, Cohen SP. Evaluation of sacroiliac joint interventions: A systematic appraisal of the literature. Pain Physician 2009; 12:399418.

83. Hayek SM, Helm S, Benyamin RM, Singh $V$, Bryce DA, Smith HS. Effectiveness of spinal endoscopic adhesiolysis in post lumbar surgery syndrome: A systematic review. Pain Physician 2009; 12:419-435.

84. Epter RS, Helm S, Hayek SM, Benyamin RM, Smith HS, Abdi S. Systematic review of percutaneous adhesiolysis and management of chronic low back pain in post lumbar surgery syndrome. Pain Physician 2009; 12:361-378.

85. Helm S, Hayek S, Benyamin RM, Manchikanti L. Systematic review of the effectiveness of thermal annular procedures in treating discogenic low back pain. Pain Physician 2009; 12:207-232.

86. Hirsch JA, Singh V, Falco FJE, Benyamin RM, Manchikanti L. Automated percutaneous lumbar discectomy for the contained herniated lumbar disc: A systematic assessment of evidence. Pain Physician 2009; 12:601-620.

87. Singh V, Manchikanti L, Benyamin RM, Helm S, Hirsch JA. Percutaneous lumbar laser disc decompression: A systematic review of current evidence. Pain Physician 2009; 12:573-588.

88. Singh V, Benyamin RM, Datta S, Falco FJE, Helm S, Manchikanti L. Systematic review of percutaneous lumbar mechanical disc decompression utilizing Dekompressor. Pain Physician 2009; 12:589-599.

89. Manchikanti L, Derby R, Benyamin RM, Helm S, Hirsch JA. A systematic review of mechanical lumbar disc decompression with nucleoplasty. Pain Physician 2009; 12:561-572.

90. Manchikanti L, Glaser S, Wolfer L, Derby $\mathrm{R}$, Cohen SP. Systematic review of lumbar discography as a diagnostic test for chronic low back pain. Pain Physician 2009; 12:541-559.

91. Frey ME, Manchikanti L, Benyamin RM, Schultz DM, Smith HS, Cohen SP. Spinal cord stimulation for patients with failed back surgery syndrome: A systematic review. Pain Physician 2009; 12:379-397.

92. Manchikanti L, Derby R, Benyamin RM, Helm S, Hirsch JA. A systematic review of mechanical lumbar disc decompression with nucleoplasty. Pain Physician 2009; 12:561-572.

93. Manchikanti L, Dunbar EE, Wargo BW, Shah RV, Derby R, Cohen SP. Systematic review of cervical discography as a diagnostic test for chronic spinal pain. Pain Physician 2009; 12:305-321.

94. Smith H, Navani A, Fishman SM. Radiopharmaceuticals for palliation of painful osseous metastases. Am J Hosp Palliat Care 2004; 21:303-313.

95. Portenoy RK, Forbes K, Lussier D, Hanks G. Difficult pain problems: An integrated approach. In Doyle D, Hanks G, Cherny 
N, Calman K (eds). Oxford Textbook of Palliative Medicine 3 rd ed. Oxford University Press, Oxford, United Kingdom, 2004, pp 438-458.

96. Davies A. Current thinking cancer breakthrough pain management. Eur J Palliat Care 2005; 12:4-6.

97. Portenoy RK, Hagen NA. Breakthrough pain: Definition, prevalence and characteristics. Pain 1990; 41:273-281.

98. Fine PG, Busch MA. Characterization of breakthrough pain by hospice patients and their caregivers. J Pain Sympt Manage 1998; 16:179-183.

99. Portenoy RK, Payne D, Jacobsen P. Breakthrough pain: Characteristics and impact in patients with cancer pain. Pain 1999; 81:129-134.

100. Zeppetella G, O'Doherty CA, Collins S. Prevalence and characteristics of breakthrough pain in cancer patients admitted to a hospice. J Pain Sympt Manage 2000; 20:87-92.

101. Fortner BV, Okon TA, Portenoy RK. A survey of pain-related hospitalizations, emergency department visits, and physician office visits reported by cancer patients with and without history of breakthrough pain. J Pain 2002; 3:38-44.

102. Gómez-Batitse $X$, Madrid F, Moreno F, Gracia A, Trelis J. Nabal M, Alcalde R, Planas J, Camell $\mathrm{H}$. Breakthrough cancer pain: Prevalence and characteristics in patients in Catalonia, Spain. J Pain Symp Manage 2002; 24:45-52.

103. Fortner BV, Demarco G, Irving G, Ashley J, Keppler G, Chavez J, Munk J. Description and predictors of direct and indirect costs of pain reported by cancer patients. J Pain Sympt Manage 2003; 25:9-18.

104. Hwang SS, Cheng VT, Kasimis B. Cancer breakthrough pain characteristics and responses to treatment at a VA medical center. Pain 2003; 101:55-64.

105. Colleau SM. Breakthrough (episodic) vs. baseline (persistent) pain in cancer. Cancer Pain Release 2004; 17:1-3.

106. Caraceni A, Martini C, Zecca E, Portenoy RK, Ashby MA, Hawson G, Jackson KA Lickiss N, Muirden N, Pisasale M, Moulin D, Schulz VN, Rico Pazo MA, Serrano JA, Andersen H, Henriksen HT, Mejholm I, Sjogren P, Heiskanen T, Kalso E, Pere P, Poyhia R, Vuorinen E, Tigerstedt I, Ruismaki P, Bertolino M, Larue F, Ranchere JY, Hege-Scheuing G, Bowdler I, Helbing F, Kostner E, Radbruch L, Kastrinaki K, Shah S, Vijayaram S, Sharma KS, Devi PS, Jain PN, Ramamani PV, Beny A, Brunelli C, Maltoni M, Mercadante S, Plancarte R, Schug S, Engstrand P, Ovalle AF, Wang X,
Alves MF, Abrunhosa MR, Sun WZ, Zhang L, Gazizov A, Vaisman M, Rudoy S, Gomez Sancho M, Vila P, Trelis J, Chaudakshetrin $P$, Koh ML, Van Dongen RT, VielvoyeKerkmeer A, Boswell MV, Elliott T, Hargus E, Lutz L; Working Group of an IASP Task Force on Cancer Pain. Breakthrough pain characteristics and syndromes in patients with cancer pain. An international survey. Palliative Med 2004; 18:177-183.

107. Portenoy RK. Supportive and palliative care. In: Straud DJ (ed). Educational Review Manual in Medical Oncology. Castle Connolly Graduate Medical Publishing, New York, New York, 2007, pp 361-408.

108. Patel VB, Manchikanti L, Singh V, Schultz DM, Hayek SM, Smith HS. Systematic review of intrathecal infusion systems for long-term management of chronic noncancer pain. Pain Physician 2009; 12:345360.

109. Raffaeli W, Sarti D, Demartini L, Sotgiu A, Bonezzi C; Italian Ziconotide Group. Italian Registry on long-term intrathecal ziconotide treatment. Pain Physician 2011; 14:15-24.

110. Moulin DE, lezzi A, Amireh R, Sharpe WK, Boyd D, Merskey H. Randomised trial of oral morphine for chronic non-cancer pain. Lancet 1996; 347:143-147.

111. Molloy AR, Nicholas MK, Asghari A, Beeston LR, Dehghani M, Cousins MJ, Brooker C, Tonkin L. Does a combination of intensive cognitive-behavioral pain management and a spinal implantable device confer any advantage? A preliminary examination. Pain Pract 2006; 6:96103.

112. Cohen SP, Dragovich A. Intrathecal analgesia. Anesthesiology Clin 2007; 25:863-882.

113. Thimineur MA, Kravitz E, Vodapally MS. Intrathecal opioid treatment for chronic nonmalignant pain: A 3-year prospective study. Pain 2004; 109:242-249.

114. Wallace M, Yaksh TL. Long-term spinal analgesic delivery: Review of the preclinical and clinical literature. Reg Anesth Pain Med 2000; 25:117-157.

115. Coffey RJ, Owens ML, Broste SK, Dubois MY, Ferrante FM, Schultz DM, Stearns LJ, Turner MS. Mortality associated with implantation and management of intrathecal opioid drug infusion systems to treat noncancer pain. Anesthesiology 2009; 111:881-891.

116. Rathmell JP, Miller MJ. Death after initiation of intrathecal drug therapy for chronic pain: Assessing risk and designing prevention. Anesthesiology 2009; 111:706-708.

117. Roberts LJ, Finch PM, Pullan PT, Bhagat $\mathrm{Cl}$, Price LM. Sex hormone suppression by intrathecal opioids: A prospective study. Clin J Pain 2002; 18:144-148.

118. Daniell HW. Opioid endocrinopathy in women consuming prescribed sustainedaction opioids for control of nonmalignant pain. J Pain 2008; 9:28-36.

119. Plummer JL, Cmielewski PL, Gourlay GK, Owen H, Cousins MJ. Antinociceptive and motor effects of intrathecal morphine combined with intrathecal clonidine, noradrenaline, carbachol or midazolam in rats. Pain 1992; 49:145-152.

120. Burton AW, Deer TR, Wallace MS, Rauck RL, Grigsby E. Considerations and methodology for trialing ziconotide. Pain Physician 2010; 16:23-33.

121. Deer TR, Kim C, Bowman R, Tolentino D, Steward C, Tolentino W. Intrathecal ziconotide and opioid combination therapy for noncancer pain: An observational study. Pain Physician 2009; 12:E291-E296.

122. Thompson JC, Dunbar E, Laye RR. Treatment challenges and complications with zicontide monotherapy in established pump patients. Pain Physician 2005; 8:147152.

123. Hassenbusch S, Burchiel K, Coffey RJ, Cousins MJ, Deer T, Hahn MB, Pen SD, Follett KA, Krames E, Rogers JN, Sagher O, Staats PS, Wallace M, Willis KD. Management of intrathecal catheter-tip inflammatory masses: A consensus statement. Pain Med 2002; 3:313-323.

124. Yennurajalingam $S$, Braiteh $F$, Bruera $E$. Pain and terminal delirium research in the elderly. Clin Geriatr Med 2005; 21:93-119.

125. Galloway D. Treating patients with cancer requires looking beyond the tumor. www2.mdanderson.org/depts/oncolog/articles/pf/04/7-8-julaug/7-8-04-3-pf. html. Accessed August 11, 2009.

126. Mercadante S. Controversies over spinal treatment in advanced cancer patients. Support Care Cancer 1998; 6:495-502.

127. World Health Organization. Cancer Pain Relief. Second Edition. With a Guide to Opioid Availability. WHO, Geneva, Switzerland, 1996, pp 36-37.

128. Meuser T, Pietruck C, Radbruch L, Stute P, Lehmann KA, Grond S. Symptoms during cancer pain treatment following WHOguidelines: A longitudinal follow-up study of symptom prevalence, severity and etiology. Pain 2001; 93:247-257.

129. Zech DF, Grond S, Lynch J, Hertel D, Lehmann KA. Validation of World Health Organization Guidelines for cancer pain relief: A 10-year prospective study. Pain 1995; 63:65-76.

130. Willis KD, Doleys DM. The effects of long 
term intraspinal infusion therapy with non-cancer pain patients: Evaluation of patient, significant-other, and clinic staff appraisals. Neuromodulation 1999; 2:241253

131. Onofrio BM, Yaksh TL. Long-term pain relief produced by intrathecal morphine infusion in 53 patients. J Neurosurg 1990; 72:200-209.

132. Onofrio BM, Yaksh TL, Arnold PG. Continuous low-dose intrathecal morphine administration in the treatment of chronic pain of malignant origin. Mayo Clin Proc 1981; 56:516-520.

133. Yaksh TL, Reddy SV. Studies in the primate on the analgetic effects associated with intrathecal actions of opiates, alpha-adrenergic agonists and baclofen. Anesthesiology 1981; 54:451-467.

134. Farney RJ, Walker JM, Cloward TV, Rhondeau S. Sleep-disordered breathing associated with long-term opioid therapy. Chest 2003; 123:632-639.

135. Krames ES, Olson K. Clinical realities and economic considerations: Patient selection in intrathecal therapy.J Pain Symptom Manage 1997; 14: $\mathrm{S}_{3}-\mathrm{S}_{13}$

136. Rozzini R, Frisoni GB, Ferrucci L, Barbisoni P, Sabatini T, Ranieri P, Guralnik JM, Trabucchi M. Geriatric Index of Comorbidity: Validation and comparison with other measures of comorbidity. Age Ageing 2002; 31:277-285.

137. Platelet transfusion guidelines. American Red Cross. www.newenglandblood.org/ professional/plateletguide.htm. Accessed October 30, 2009.

138 Physicians' Desk Reference 62nd ed. Thomson PDR, Montvale, NJ, 2008, page 1198.

139. Risdahl JM, Khanna KV, Peterson PK, Molitor TW. Opiates and infection.] Neuroimmunol 1998; 83:4-18.

140. Del Pozo JL, Patel R. Clinical practice: Infection associated with prosthetic joints. $N$ Engl J Med 2009; 361:787-794.

141. Mangram AJ, Horan TC, Pearson ML, Silver LC, Jarvis WR. Guideline for Prevention of Surgical Infection, Infection Control and Hospital Epidemiology, Vol 20, No 4, 247-78.

142. Rathmell JP, Lake T, Ramundo MB. Infectious risks of chronic pain treatments: Injection therapy, surgical implants, and intradiscal techniques. Reg Anesth Pain Med 2006; 31:346-352.

143. Streiff MB. Diagnosis and initial treatment of venous thromboembolism in patients with cancer. J Clin Oncol 2009; 27:4889-4894.
144. Horlocker $T T$, Wedel $D J$, Benzon $\mathrm{H}$, Brown DL, Enneking FK, Heit JA, Mulroy MF, Rosenquist RW, Rowlingson J, Tryba M, Yuan CS. Regional anesthesia in the anticoagulated patient: Defining the risks (the Second ASRA Consensus Conference on Neuraxial Anesthesia and Anticoagulation). Reg Anesth Pain Med 2003; 28:172197.

145. Chaney MA. Intrathecal and epidural anesthesia and analgesia for cardiac surgery. Anesth Analg 2006; 102:45-64.

146. Preventing errors relating to commonly used anticoagulants. The Joint Commission. www.jointcommission.org/SentineIEvents/SentinelEventAlert/sea_41.htm. Accessed July 28, 2009.

147. Diabetes Statistics. American Diabetes Association. www.diabetes.org/diabetes-basics/diabetes-statistics. Accessed November 4, 2009.

148. Diabetic neuropathies: The nerve damage of diabetes. National Diabetes Information Clearinghouse (NDIC). diabetes.niddk.nih.gov/dm/pubs/neuropathies/index. $\mathrm{htm}$. Accessed July 28, 2009.

149. Jee SH, Ohrr H, Sull JW, Yun JE, Ji M, Samet JM. Fasting serum glucose level and cancer risk in Korean men and women. JAMA 2005; 293:194-202.

150. Greenhalgh DG. Wound healing and diabetes mellitus. Clin Plast Surg 2003; 30:3745 .

151. Van den Berghe G. How does blood glucose control with insulin save lives in intensive care? J Clin Invest 2004; 114:11871195.

152. Ogden $\mathrm{CL}$, Carrol MD, McDowell MA, Flegal KM. Obesity among adults in the United States-no statistically significant chance since 2003-2004. NCHS Data Brief 2007; 1:1-8.

153. Obstructive sleep apnea and sleep. National Sleep Foundation. www.sleepfoundation.org/article/sleep-related-problems/obstructive-sleep-apnea-and-sleep. Accessed August 11, 2009.

154. Webster LR, Choi Y, Desai H, Webster L, Grant BJ. Sleep-disordered breathing and chronic opioid therapy. Pain Med 2008; 9:425-432.

155. American Society of Anesthesiologists Task Force on Neuraxial Opioids, Horlocker TT, Burton AW, Connis RT, Hughes SC, Nickinovich DG, Palmer CM, Pollock JE, Rathmell JP, Rosequist RW, Swisher JL, Wu CL. Practice guidelines for the prevention, detection, and management of respiratory depression associated with neuraxial opioid administration. Anesthesiology
2009; 110:218-230.

156. Pergolizzi J, Boger RH, Budd K, Dahan A, Erdine S, Hans G, Kress HG, Langford R, Likar R, Raffa RB, Sacerdote P. Opioids and the management of chronic severe pain in the elderly: Consensus statement of an international expert panel with focus on the six clinically most often used World Health Organization step III opioids (buprenorphine, fentanyl, hydromorphone, methadone, morphine, oxycodone). Pain Pract 2008; 8:287-313.

157. Berger NA, Savvides P, Koroukian SM, Kahana $\mathrm{EF}$, Deimling GT, Rose JH, Bowman $\mathrm{KF}$, Miller RH. Cancer in the elderly. Trans Am Clin Climatol Assoc 2006; 117:147-155.

158. Urban D, Cherny N, Catane R. The management of cancer pain in the elderly. Crit Rev Oncol Hematol 2010; 73:176-183.

159. Stein WM, Miech RP. Cancer pain in the elderly hospice patient. J Pain Symptom Manage 1993; 8:474-482.

160. Buntin-Mushock C, Phillip L, Moriyama K, Palmer PP. Age-dependent opioid escalation in chronic pain patients. Anesth Analg 2005;100: 1740-1745.

161. National diabetes fact sheet, 2007. Centers for Disease Control and Prevention. www.cdc.gov/diabetes/pubs/pdf/ ndfs_2007.pdf. Accessed August 11, 2009.

162. Cancer Facts and Figures 2003. American Cancer Society. www.cancer.org/downloads/STT/CAFF2003PWSecured.pdf. Accessed October 15, 2009.

163. Turk DC, Monarch ES, Williams AD. Cancer patients with pain: Considerations for assessing the whole person. Hematological Oncol Clin N Am 2002; 16:511-525.

164. Kroner K, Krebs B, Skov J, Jorgensen HS. Immediate and long term phantom breast syndrome after mastectomy: Incidence, clinical characteristic relationship to pre-mastectomy breast pain. Pain 1989; 36:327-335.

165. Barkwell DP. Ascribed meaning: A critical factor in coping and pain attenuation in patients with cancer-related pain.J Palliat Care 1991; 7:5-14.

166. Spiegel D, Bloom JR. Group therapy and hypnosis reduced metastatic breast carcinoma pain. Psychosom Med 1982; 45:333339.

167. Ahles TA, Blanchard EB, Ruckdeschel JC. The multidimensional nature of cancerrelated pain. Pain 1983; 17:277-288.

168. Zaza C, Baine N. Cancer pain and psychological factors: A critical review of the literature. J Pain Symptom Manage 2002; 24:526-542. 
169. Glover J, Dibble SL, Dodd MJ, Miaskowski C. Mood states of oncological outpatients: Does pain make a difference? J Pain Symptom Manage 1995; 10:120-128.

170. Kane RL, Berstein L, Wales J, Rothenberg R. Hospice effectiveness in controlling pain. JAMA 1985; 253:2683-6.

171. Kelsen DP, Portenoy RK, Thaler HT, Niedzwiecki D, Passik SD, Tao Y, Banks W, Brennan MF, Foley KM. Pain and depression in patients with newly diagnosed pancreas cancer. J Clin Oncol 1995; 13:748-755.

172. Steinman RH. The cancer patient with anxiety and chronic pain. Pain: Clinical Updates 2009; 27:1-5.

173. Monroe B. Psychological evaluation of patient and family. In Sykes N, Fallon MT, Patt RB (eds). Clinical Pain Management: Cancer Pain. Oxford University Press, New York, New York, 2003, pp 73-85.

174. Rathbone GV, Horsley S, Goacher J. A selfevaluated assessment suitable for seriously ill hospice patients. Palliat Med 1994; 8:29-34

175. Endicott J. Measurement of depression in patients with cancer. Cancer 1984; 53:22432249.

176. Casey P. Depression in the dying-disorder or distress? Prog Palliative Care 1994; 2:1-3.

177. Moorey S, Greer S, Watson M, Gorman C, Rowden L, Tunmore R, Robertson B, Bliss J. The factor structure and factor stability of the Hospital Anxiety and Depression Scale with cancer. Br] Psychiatry 1991; 158:255-259.

178. Daunt RJ, Cleeland CS, Flannery RC. Development of the Wisconsin Brief Pain Questionnaire to assess pain in cancer and other diseases. Pain 1983; 17:197-210.

179. Karnofsky DA, Abelmann WH, Craver $L F$, Burchenal JH. The use of the nitrogen mustards in the palliative treatment of carcinoma. With particular reference to bronchogenic carcinoma. Cancer 1948; 1:634-656.

180. Ware JE, Kosinki M, Keller SD. SF-36 Physical and Mental Health Summary Scales: A User's Manual. The Health Institue, Boston, Massachusetts, 1994.

181. Hamilton M. The assessment of anxiety states by rating. $\mathrm{Br}$ J Med Psychol 1959; 32:50-55.

182. Derogatis LR, Morow GR, Fetting J, Penman D, Piasetsky S, Schmale AM, Henrichs $\mathrm{M}$, Carnicke $\mathrm{CL}$ Jr. The prevalence of psychiatric disorders among cancer patients. JAMA 1983; 249:751-757.

183. Massie MJ, Holloand JC. The cancer patient with pain: Psychiatric complications and their management. J Pain Symptom Manage 1992; 7:99-109.

184. Asmundson GJ, Coons MJ, Taylor S, Katz J. PTSD and the experience of pain: Research and clinical implications of shared vulnerability and mutual maintenance models. Can J Psychiatry 2002; 47:930-937.

185. Keogh E, Cochrane M. Anxiety sensitivity, coping biases and the experience of pain. J Pain 2002; 3:320-329.

186. Miller K, Massie MJ. Depression and anxiety. Cancer ] 2006; 12:388-397.

187. Cahana A. Is optimal pain relief always optimal? APS Bull 2002; 12:3.

188. Ward SE, Goldberg N, Miller-McCauley V, Mueller C, Nolan A, Pawlik-Plank D, Robbins 188.1A, Stormoen D, Weissman DE. Patient-related barriers to management of cancer pain. Pain 1993; 52:319-324.

189. Ward SE, Carlson-Dakes K, Hughes SH, Kwekkeboom KL, Donovan HS. The impact of quality of life on patient-related barriers to pain management. Res Nurs Health 1998; 21:5-13.

190. Ahmed SU, Martin NM, Chang Y. Patient selection and trial methods for intraspinal drug delivery for chronic pain: A national survey. Neuromodulation 2005; 8:112-120.

191. Keefe FJ, Abernethy AP, Campbell L. Psychological approaches to understanding and treating disease-related pain. Annu Rev Psychol 2005; 56:601-630.

192. Burton AW, Fanciullo GJ, Beasley RD, Fisch MJ. Chronic pain in the cancer survivor: A new frontier. Pain Med 2007; 8:189198.

193. Deer T, Ranson M, Stewart D. Relevant anatomy for spinal delivery. In: Krames $E$, Hunter Peckham P, Rezai A (eds). Neuromodulation. Elsevier, New York, New York, 2009.

194. Follett KA, Burchiel K, Deer T, Stuart DuPen, Joshua Prager, Michael S. Turner and Robert J. Coffey. Prevention of intrathecal drug delivery catheter-related complications. Neuromodulation 2003; 6:32-41.

195. Carr DB, Cousins MJ. Spinal route of analgesia: Opioids and future options for spinal analgesic chemotherapy. In: Cousins MJ, Carr DB, Horlocker TT, Bridenbaugh PO (eds). Neural Blockade in Clinical Anesthesia and Pain Medicine $4^{\text {th }}$ ed. Wolters Kluwer Lippincott Williams \& Wilkins, Philadelphia, Pennsylvania, 2008, pp 886947.

196. Relative survival rates by year of diagnosis. National Cancer Institute. seer.cancer. gov/csr/1975_2005/results_merged/topic_ survival_by_year_dx.pdf. Accessed October 7,2009 .
197. Levy MH, Chwistek M, Mehta RS. Management of chronic pain in cancer survivors. Cancer ] 2008; 14:401-409.

198. Abernethy AP, Wheeler JL, Fortner BV. A health economic model of breakthrough pain. Am J Manag Care 2008; 14:S129Si4o.

199. Prescription Price Center (2009). www. drugstore.com/pharmacy/drugindex. Accessed April 3, 2009.

200. Intrathecal drug delivery for chronic pain: Physician commonly billed codes. Medtronic for Healthcare Professionals. (January 2009). professional.medtronic. com/downloads/idd/idd-physician-common-codes.pdf. Accessed April 15, 2009.

201 Intrathecal drug delivery for chronic pain: Hospital commonly billed codes. Medtronic for Healthcare Professionals. (January 2009). professional.medtronic. com/downloads/idd/idd-hospital-common-codes.pdf. Accessed April 15, 2009.

202. Medicare Part B Drug Average Sales Price. 2009 ASP Drug Pricing Files. Centers for Medicare \& Medicaid Services. www.cms. hhs.gov/McrPartBDrugAvgSalesPrice. Accessed April 21, 2009.

203. Bedder MD, Burchiel K, Larson A. Cost analysis of two implantable narcotic delivery systems. J Pain Symptom Manage 1991; 6:368-373.

204. De Lissovoy G, Brown RE, Halpern M, Hassenbusch SJ, Ross E. Cost-effectiveness of long-term intrathecal morphine therapy for pain associated with failed back surgery syndrome. Clin Ther 1997; 19:96-112.

205. Federal Register. Hospital outpatient rates. Volume 73, Number 193, October 3, 2008.

206. Federal Register. Physician rates. Volume 73, Number 224, November 19, 2008.

207. Deer TR, Smith HS, Cousins M, Doleys DM, Levy RM, Rathmell JP, Staats PS, Wallace M, Webster LR. Consensus guidelines for the selection and implantation of patients with noncancer pain for intrathecal drug delivery. Pain Med Unpublished data. In press.

208 Actiq. Drugstore.com. http://www.drugstore.com/pharmacy/prices/drugprice. asp?ndc $=63459050430 \&$ trx $=1 Z_{5006}$. Accessed October 30, 2009.

209. PMA-premarket approval. US Food and Drug Administration. www.accessdata. fda.gov/scripts/cdrh/cfdocs/cfPMA/PMA. cfm?ID=4499. Accessed May 8, 2009.

210. Rainov NG, Buchser E. Making a case for programmable pumps over fixed rate pumps for the management of fluctua- 
tions in chronic pain and spasticity: A literature review. Neuromodulation 2002; 5:8999.

211. Ilias W, Todoroff B. Optimizing pain control through the use of implantable pumps. Medical Devices: Evidence and $\mathrm{Re}$ search 2008; 1:41-47.

212. Prager J, Jacobs M. Evaluation of patients for implantable pain modalities: Medical and behavioral assessment. Clin J Pain 2001; 17:206-214.

213. Levy RM. Quantitative, crossover, doubleblind trial paradigm for patient screening for chronic intraspinal narcotic administration. Neurosurg Focus 1997; 2:e2.

214. Rosenstiel AK, Keefe FJ. The use of coping strategies in chronic low back pain patients: Relationship to patient characteristics and current adjustment. Pain 1983; 17:33-44.

215. Dominguez E, Sahinler B, Bassam D, Day M, Lou L, Racz G, Raj P. Predictive value of intrathecal narcotic trials for long-term therapy with implantable drug administration systems in chronic non-cancer pain patients. Pain Pract 2002; 2:315-325.

216. Hassenbusch SJ, Stanton-Hicks M, Covington EC, Walsh JG, Guthrey DS. Longterm intraspinal infusions of opioids in the treatment of neuropathic pain. J Pain Symptom Manage 1995; 10:527-543.

217. Yoshida GM, Nelson RW, Capen DA, Nagelberg S, Thomas JC, Rimoldi RL, Haye W. Evaluation of continuous intraspinal narcotic analgesia for chronic pain from benign causes. Am J Orthop (Belle Meade NJ) 1996; 25:693-694.

218. Follett KA, Doleys DM. Selection of candidates for intrathecal drug administration to treat chronic pain: considerations in pre-implantation trials. Minneapolis, $\mathrm{MN}$ : Medtronic, Inc; 2002. )

219. Medicare Coverage Issues Manual. Coverage issues-durable medical equipment. www.cms.hhs.gov/manuals/downloads/ Pubo6_PART_6o.pdf Accessed August 19, 2009.

220. Hassenbusch SJ, Portenoy RK, Cousins M, Buchser E, Deer TR, Du Pen SL, Eisenach J, Follett KA, Hildebrand KR, Krames ES, Levy RM, Palmer PP, Rathmell JP, Rauck RL, Staats PS, Stearns L, Willis KD. Polyanalgesic Consensus Conference 2003: An update on the management of pain by intraspinal drug delivery-report of an expert panel. J Pain Symptom Manage 2004; 27:540-563.

221. Crul BJ, Delhaas EM. Technical complications during long-term subarachnoid or epidural administration of morphine in terminally ill cancer patients: A review of 140 cases. Reg Anesth 1991; 16:209-213.

222. van Kleef M, Mekhail N, van ZundertJ. Evidence based guidelines for interventional pain medicine according to clinical diagnoses. Pain Pract 2009; 9:247-251.

223. Guyatt G, Gutterman D, Baumann MH, Addrizzo-Harris D, Hylek EM, Phillips B, Raskob G, Lewis SZ, Schunemann H. Grading strength of recommendations and quality of evidence in clinical guidelines: Report from an American College Of Chest Physicians Task Force. Chest 2006; 129:174-181.

224. Graham R, Mancher M, Wolman DM, Greenfield S, Steinberg E (eds); Committee on Standards for Systematic Reviews of Comparative Effectiveness Research; Institute of Medicine. Clinical Practice Guidelines We Can Trust. The National Academies Press, Washington, DC, 2011.

225. Eden J, Levit L, Berg A, Morton S (eds); Committee on Standards for Systematic Reviews of Comparative Effectiveness Research; Institute of Medicine. Finding What Works in Health Care. Standards for Systematic Reviews. The National Academies Press, Washington, DC, 2011.

226. Manchikanti L, Hirsch JA, Smith HS. Evidence-based medicine, systematic reviews, and guidelines in interventional pain management: Part 2: Randomized controlled trials. Pain Physician 2008; 11:717-773.

227 Manchikanti L, Benyamin RM, Helm S, Hirsch JA. Evidence-based medicine, systematic reviews, and guidelines in interventional pain management: Part 3: Systematic reviews and meta-analysis of randomized trials. Pain Physician 2009; 12:3572

228. Manchikanti L, Singh V, Smith HS, Hirsch JA. Evidence-based medicine, systematic reviews, and guidelines in interventional pain management: Part 4: Observational studies. Pain Physician 2009; 12:73-108.

229. Manchikanti L, Derby R, Wolfer LR, Singh V, Datta S, Hirsch JA. Evidence-based medicine, systematic reviews, and guidelines in interventional pain management: Part 5. Diagnostic accuracy studies. Pain Physician 2009; 12:517-540.

230. Manchikanti L, Datta S, Smith HS, Hirsch JA. Evidence-based medicine, systematic reviews, and guidelines in interventional pain management: Part 6. Systematic reviews and meta-analyses of observational studies. Pain Physician 2009; 12:819-850.

231. Manchikanti L, Derby R, Wolfer LR, Singh V, Datta S, Hirsch JA. Evidence-based medicine, systematic reviews, and guidelines in interventional pain management: Part 7: Systematic reviews and meta-analyses of diagnostic accuracy studies. Pain Physician 2009; 12:929-963.

232. Manchikanti L, Falco FJE, Boswell MV, Hirsch JA. Facts, fallacies, and politics of comparative effectiveness research: Part 1. Basic considerations. Pain Physician 2010; 13:E23-E54.

233. Manchikanti L, Falco FJE, Boswell MV, Hirsch JA. Facts, fallacies, and politics of comparative effectiveness research: Part 2. Implications for interventional pain management. Pain Physician 2010; 13:E55-E79.

234. Manchikanti L, Datta S, Derby R, Wolfer LR, Benyamin RM, Hirsch JA. A critical review of the American Pain Society clinical practice guidelines for interventional techniques: Part 1. Diagnostic interventions. Pain Physician 2010; 13:E141-E174.

235. Manchikanti L, Datta S, Gupta S, Munglani R, Bryce DA, Ward SP, Benyamin RM, Sharma ML, Helm II S, Fellows B, Hirsch JA. A critical review of the American Pain Society clinical practice guidelines for interventional techniques: Part 2. Therapeutic interventions. Pain Physician 2010; 13:E215-E264.

236. Benyamin RM, Datta S, Falco FJE. A perfect storm in interventional pain management: Regulated, but unbalanced. Pain Physician 2010; 13:109-116.

237. Manchikanti L, Singh V, Boswell MV. Interventional pain management at crossroads: The perfect storm brewing for a new decade of challenges. Pain Physician 2010; 13:Eı11-E140.

238. Manchikanti L, Singh V, Pampati V, Smith HS, Hirsch JA. Analysis of growth of interventional techniques in managing chronic pain in Medicare population: A 10-year evaluation from 1997 to 2006. Pain Physician 2009; 12:9-34.

239. Manchikanti L, Pampati V, Singh V, Boswell MV, Smith HS, Hirsch JA. Explosive growth of facet joint interventions in the Medicare population in the United States: A comparative evaluation of 1997, 2002, and 2006 data. BMC Health Serv Res 2010; 10:84.

240 Manchikanti L, Pampati V, Boswell MV, Smith HS, Hirsch JA. Analysis of the growth of epidural injections and costs in the Medicare population: A comparative evaluation of 1997, 2002, and 2006 data. Pain Physician 2010; 13:199-212. 